\title{
Synthesis of graphene-transition metal oxide hybrid nanoparticles and their application in various fields
}

\author{
Arpita Jana ${ }^{* 1,2}$, Elke Scheer ${ }^{2}$ and Sebastian Polarz ${ }^{1}$
}

\author{
Review \\ Address: \\ ${ }^{1}$ Department of Chemistry, University of Konstanz, 78457 Konstanz, \\ Germany and ${ }^{2}$ Department of Physics, University of Konstanz, 78457 \\ Konstanz, Germany \\ Email: \\ Arpita Jana* - arpita.jana@uni-konstanz.de \\ * Corresponding author \\ Keywords: \\ graphene; hybrid; nanoparticle; reduced graphene oxide; transition \\ metal oxide
}

Beilstein J. Nanotechnol. 2017, 8, 688-714.

doi:10.3762/bjnano.8.74

Received: 07 December 2016

Accepted: 06 February 2017

Published: 24 March 2017

Associate Editor: A. Gölzhäuser

(C) 2017 Jana et al.; licensee Beilstein-Institut. License and terms: see end of document.

\begin{abstract}
Single layer graphite, known as graphene, is an important material because of its unique two-dimensional structure, high conductivity, excellent electron mobility and high surface area. To explore the more prospective properties of graphene, graphene hybrids have been synthesised, where graphene has been integrated with other important nanoparticles (NPs). These graphene-NP hybrid structures are particularly interesting because after hybridisation they not only display the individual properties of graphene and the NPs, but also they exhibit further synergistic properties. Reduced graphene oxide (rGO), a graphene-like material, can be easily prepared by reduction of graphene oxide (GO) and therefore offers the possibility to fabricate a large variety of graphene-transition metal oxide (TMO) NP hybrids. These hybrid materials are promising alternatives to reduce the drawbacks of using only TMO NPs in various applications, such as anode materials in lithium ion batteries (LIBs), sensors, photocatalysts, removal of organic pollutants, etc. Recent studies have shown that a single graphene sheet (GS) has extraordinary electronic transport properties. One possible route to connecting those properties for application in electronics would be to prepare graphene-wrapped TMO NPs. In this critical review, we discuss the development of graphene-TMO hybrids with the detailed account of their synthesis. In addition, attention is given to the wide range of applications. This review covers the details of graphene-TMO hybrid materials and ends with a summary where an outlook on future perspectives to improve the properties of the hybrid materials in view of applications are outlined.
\end{abstract}

\section{Review}

\section{Introduction}

Graphene consists of a single layer of carbon in a two-dimensional (2D) lattice. It is a densely packed, atomically thin layer of $\mathrm{sp}^{2}$ hybridised carbon atoms arranged in a honeycomb network. Since the first report in 2004 [1], graphene has attracted great interest in the scientific community due to its unique properties such as superior charge carrier mobility, high 
transparency, excellent flexibility, and extraordinary electronic quality, and its superior thermal and mechanical properties [2,3]. Graphene exhibits high mechanical strength (>1060 GPa) and an exceptional Young's modulus of $1 \mathrm{TPa}$ [4]. Furthermore, single layer graphene is the strongest material ever tested [5]. It also exhibits excellent thermal $\left(\approx 5000 \mathrm{~W} \cdot \mathrm{m}^{-1} \cdot \mathrm{K}^{-1}\right)[6]$ and electrical conductivity (up to $6000 \mathrm{~S} \cdot \mathrm{cm}^{-1}$ ) [7] and high theoretical specific surface area $\left(2630 \mathrm{~m}^{2} \cdot \mathrm{g}^{-1}\right)$ [8]. Graphene is highly optically transparent (transmittance $\approx 97.7 \%$ ) with absorption of $<2.3 \%$ for visible light [9] and negligible reflectance $(<0.1 \%)$, practically independent of the wavelength [10]. Due to these superior properties, it holds great promise for potential applications in many technological fields such as nanoelectronics [11], hydrogen storage, supercapacitors [12] and sensors [13]. Despite its many interesting properties, graphene has a strong tendency to agglomerate due to van der Waals interaction between the graphene layers, which inhibits its application is various fields - this drawback can be eliminated by hybridising graphene with NPs. Graphene is a zero band gap material and the main disadvantage of using graphene alone as a catalyst is its susceptibility to oxidative environments.

In the last few decades, the synthesis of transition metal oxide (TMO) NPs has attracted much attention, providing the advantages of controlled shape, size, crystallinity and functionality, as well as being ecologically benign, corrosion resistance, easily scalable and relatively cost effective [14-16]. In particular, among all the TMO NPs, titanium dioxide [17], manganese oxide [18], iron oxide [19] and zinc oxide [20] have attracted the most attention due to their particular interesting and advantageous properties. By changing the reaction conditions in the synthesis process, such as reaction time, temperature, and precursor concentration, the morphology and size of these TMO NPs can be tuned, resulting in different and unique properties. These materials have a wide range of applications in electronics, optics, electrochemical, solar energy harvesting and so on. In order to further enhance their properties, TMO NPs have been hybridised with graphene where some disadvantages of the NPs can be offset by graphene. The common drawbacks of semiconductor NPs include their relatively low conductivity and high recombination rate of photogenerated electron-hole pairs. Additionally, the NPs result in a large volume expansion during the Li insertion-extraction process in LIB applications which hamper their use in applications such as energy storage, sensing, advanced catalysis, solar cells, diodes and also in biometrics. Thus, strongly coupled graphene-NP hybrid systems appear promising to overcome these problems.

The interest in preparing graphene-TMO NPs hybrids is increasing enormously due to the peculiarities in combining the required properties of building blocks for a specified applica- tion. In the recent review by Khan et al., the synthesis, properties and applications of graphene-metal oxide composite NPs are discussed in detail [21]. The review by Yin et al. focusses on graphene-NP-based hybrid sensors [22], while Xiang et al. review the state of the art in graphene-semiconductor photocatalysts [23]. In this review, we comprehensively discuss the different methods for the synthesis of graphene and graphene-NP hybrid systems, but do not cover graphene-NPs composite materials. We then separately review the synthesis, the morphology of graphene-TMO NP hybrids of first row, d-block element oxides, and their applications in various fields.

\section{Material property requirements for specific applications}

Graphite is commercially used as an anode material for LIBs due to its large lithium storage capacity of $372 \mathrm{mAh} \cdot \mathrm{g}^{-1}$. However, this is not sufficient for applications requiring high energy capacity. Single layer graphene has a high theoretical lithium storage capacity of $744 \mathrm{mAh} \cdot \mathrm{g}^{-1}$, but graphene has a tendency to stack due to van der Waals interactions between graphene layers [24]. The incorporation of TMO NPs inhibits the aggregation of graphene layers [25]. Poizot et al. first introduced the concept of utilising electrodes made of NPs of transition metal (e.g., $\mathrm{Co}, \mathrm{Ni}, \mathrm{Cu}, \mathrm{Fe}$ ) oxides for LIB applications by using $2 \mu \mathrm{m}$ cobalt oxide ( $\mathrm{CoO})$ particles, achieving an electrochemical capacity of $700 \mathrm{mAh} \cdot \mathrm{g}^{-1}$ with $100 \%$ capacity retention for up to 100 cycles [26]. For metal oxide in LIB applications, volume expansion occurs during the Li insertion and extraction process, which results in decreased cyclability and rate capabilities [27]. These drawbacks can be overcome by the incorporation of graphene with TMO. As mentioned above, graphene has a relatively large capacity, much higher than commercial graphite. The high conductivity and large surface area of graphene help to maintain the mechanical strength of the hybrid during the $\mathrm{Li}$ insertion and extraction process.

Graphene is used as a supercapacitor because of its unique properties, such as high surface area, excellent flexibility, chemical inertness and good electrical conductivity [28]. The practical use of the entire surface area of a graphene sample is difficult so it is often used in combination with an active metal oxide for application as an electrode material in supercapacitors. The main drawback of graphene for optical applications is its zero band gap. However, the development of a heterostructure with a direct band gap semiconductor allows this material to be applied in light emitting diodes (LEDs). In most cases, the other counterpart of graphene-NP hybrids are either transition metal or metal oxide NPs. However, in some cases, depending on the scientific requirements, multicomponent NPs have been also integrated with graphene, but such examples are still very few to date [29]. 
In a photovoltaic cell, sunlight energy is directly converted to electricity. Graphene and graphene-NP hybrids have been investigated extensively in the field of solar cells because of their unique properties, such as high optical transparency, electrical conductivity, and mechanical flexibility. As mentioned before, graphene is an excellent electron-accepting and electron-transporting material. When graphene is integrated with semiconductor materials, it promotes photogenerated electrons through $\pi-\pi$ bond interactions and suppresses the charge recombination in the semiconductor materials [30]. As a consequence, improved photocatalytic properties of the hybrid system have been demonstrated.

\section{Synthesis of graphene}

The first free-standing single-layer graphene was obtained in 2004 by the isolation of graphene from graphite by micromechanical cleavage [1]. Later, graphene was prepared in bulk from graphite utilising various approaches, including micromechanical exfoliation of pyrolytic graphite [31-33] (the scotch tape method), epitaxial growth [34], chemical vapour deposition (CVD) $[35,36]$, and different chemical functionalisation processes $[37,38]$. Graphene prepared by the first three pro- cesses has the highest quality in terms of structure and properties. The different processes for the synthesis of graphene can be classified into two main categories: bottom-up approaches and top-down approaches (Figure 1). Bottom-up growth of graphene includes micromechanical exfoliation of bulk graphite. The processes included in the bottom-up synthesis of graphene are CVD [39,40], arc discharge [41], and epitaxial growth [42]. Using CVD, graphene and few-layer graphene have been grown on catalytic metal surfaces from carbon containing gasses. In terms of production, the CVD method is used for the production of graphene with a large area with low defect concentration, but in small quantities. Reina et al. have prepared 1- to 12-layer graphene having continuous films with up to $\approx 20 \mu \mathrm{m}$ in lateral size by using ambient pressure CVD on polycrystalline $\mathrm{Ni}$; this was transferred to a variety of substrates like $\mathrm{SiO}_{2} / \mathrm{Si}$ or glass [36]. For the preparation of graphene-NP hybrids, bulk quantities of GSs are required. Therefore, for the synthesis of graphene-NP hybrid systems, top-down approaches have been used in most cases.

The most common top-down approach for the synthesis of graphene is the reduction of GO and of graphite fluoride by

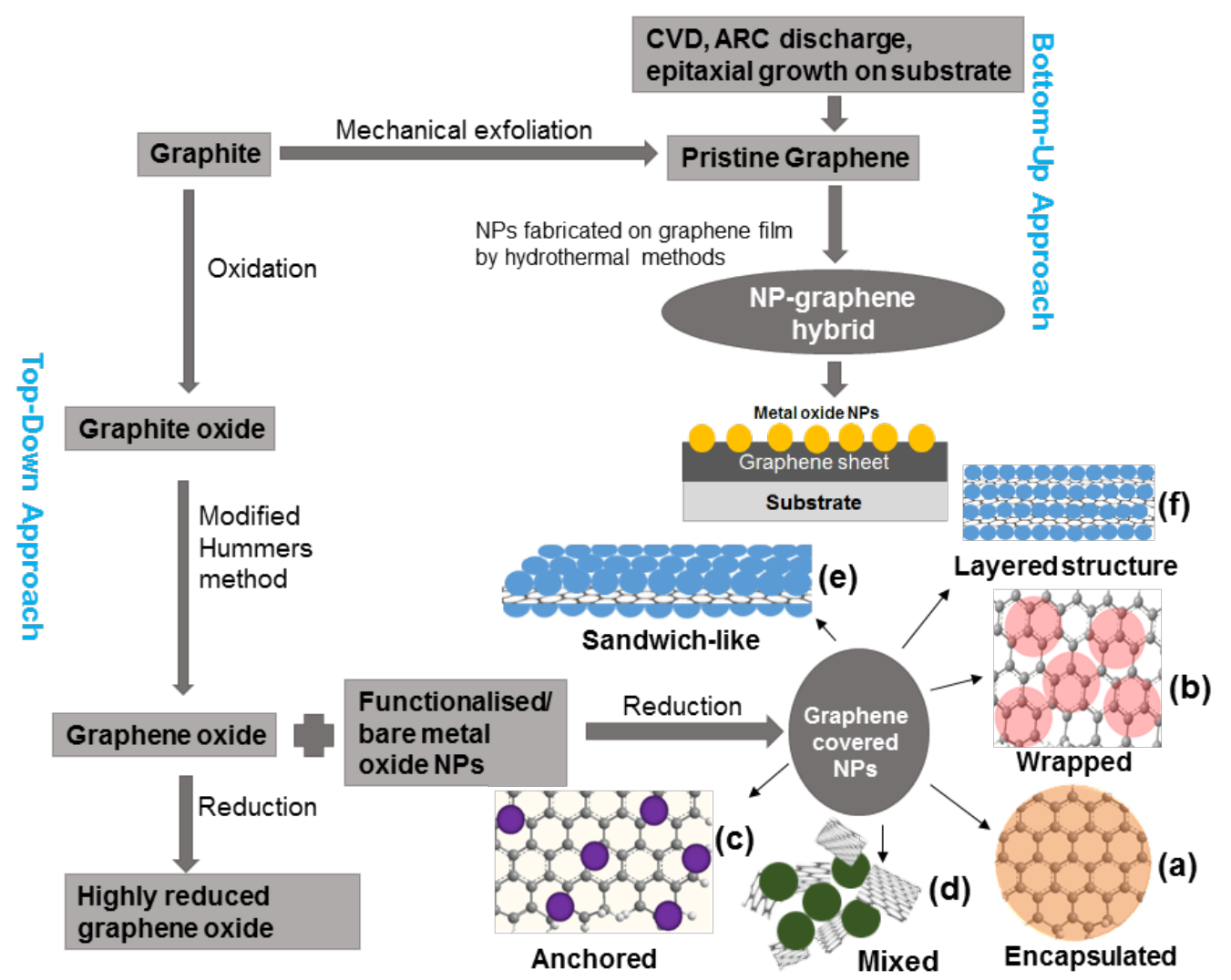

Figure 1: Schematic presentation of methods used for the formation of graphene-NP hybrids and different structures of (a) graphene-encapsulated NPs, (b) graphene-wrapped NPs, (c) NPs anchored to GSs, (d) mixed graphene-NP structures, (e) graphene-NP sandwich structures, and (f) graphene-NP layered hybrids. 
thermal or chemical methods. The reduction of GO is a low cost, facile technique and yields bulk quantities of GSs. GO was first reported 150 years ago [43]. It is now being reinvestigated and receiving intense research interest due to its extensive use as a precursor for the large-scale synthesis of graphene and graphene-based materials. Initially, GO was prepared from inexpensive graphite as a raw starting material by the cost effective and scalable, modified Hummers method [44]. Using oxidation and exfoliation of this graphite oxide, followed by a reduction process, graphene can be achieved as highly rGO. Like graphite, GO has a layered structure, but the plane of the carbon atoms are heavily decorated by oxygen-containing groups which expand the interlayer distance and make graphite oxide hydrophilic. Exfoliated GO has only one or few layers of carbon atoms like graphene. GO can be reduced to graphene by removing the oxygen-containing groups with the recovery of the conjugated structure. Different reduction processes have been introduced to convert GO to graphene and different reduction processes result in different properties of graphene, which in turn affect the final product and also the performance of the material [45]. Reduced GO is chemically derived graphene, which is also referred to as functionalised graphene [46], chemically modified graphene [47], rGO [48], chemically converted graphene [49], or reduced graphene [50]. For the chemical reduction of GO, hydrazine monohydrate and dimethylhydrazine have been used extensively as they do not react with water and have the attractive option for reducing GO in an aqueous dispersion [51-53]. Though hydrazine effectively removes the oxygen functional group from GO, it also introduces heteroatom impurities such as $\mathrm{N}_{2}$ which form amines, hydrazones or other similar functional groups covalently attached on the sheet of graphene [54]. $\mathrm{NaBH}_{4}$ has been demonstrated as being more effective than hydrazine as a reducing agent of GO. $\mathrm{NaBH}_{4}$ is more effective at reducing the $\mathrm{C}=\mathrm{O}$ group, while it has moderate efficiency in the reduction of epoxide and carboxylic acid [55]. Other reductants used for the chemical transformation of $\mathrm{GO}$ to graphene are hydroquinone [56], gaseous $\mathrm{H}_{2}$ [57], alkaline solution [58,59], and ascorbic acid [60]. Despite the chemical reagent reduction, other reduction processes are used for the conversion of GO to graphene, e.g., microwave irradiation $[61,62]$, electrochemical reduction $[63,64]$, thermal annealing $[46,65]$, photocatalytic reduction [66], solvothermal reduction $[67,68]$, thermal deoxygenation [69], or chemical deoxygenation [70]. In terms of electrical conductivity, the quality of reduced graphene is lower than the GS prepared by CVD. The intrinsic quality of CVD graphene films makes them an excellent candidate for optoelectronic and electronic applications. In brief, the reduction method fits better for the production of small GSs, and for larger GSs, the CVD process is more efficient. Thus, depending on the application need of graphene, a suitable fabrication method could be selected.

\section{Synthesis and architecture of graphene-NP hybrids}

For the preparation of graphene-NP hybrids, bulk quantities of GSs are required. So, for the synthesis of graphene-NP hybrid systems, in most cases, top-down approaches have been used. Different architectures of graphene-NP hybrids can be prepared by this one-pot synthesis method [71]. In another process for the synthesis of graphene-NP hybrids, graphene or NPs could be chemically functionalised firstly and then NPs could be conjugated to the graphene surface by covalent or noncovalent interaction [72,73]. Graphene is flexible and has a unique 2D sheet-like structure. These sheets can be easily used to wrap or encapsulate NPs with diameters from the nanometre to even the micrometre range. The encapsulated structure is comprised of a single NP encapsulated by a single GS (Figure 1a), whereas a wrapped structure refers to the case where more than one NP is covered by multiple GSs (Figure 1b) [74]. Grapheneencapsulated and -wrapped structures have advantages compared to bare NPs, including reduced NP agglomeration, as well as increased electrical, electrochemical and optical properties. Encapsulating NPs with graphene increases the surface-tovolume ratio that is available for sensing [75]. Furthermore, the presence of graphene results in extremely high carrier mobility, high carrier density, and low intrinsic noise for better detection by virtue of the high signal-to-noise ratio. In the anchored structure, electroactive NPs are anchored on the GS (Figure 1c) [76], and in the mixed structure, the graphene and NPs are synthesised separately and mixed mechanically for application needs in various fields (Figure 1d) (although mainly used for electrode preparation in LIB applications). In the sandwich structure, graphene is used as a template to generate the active NP/graphene sandwich structure (Figure 1e) [77], and in the layer structure, graphene and NPs (Figure 1f) [27] are alternated. Most research effort has been directed towards the improvement of the quality of rGO in order to ameliorate the properties of graphene [45]. Here, different semiconductor NPs are integrated for different application aspects. To make the discussion more precise, in the following, we categorise the graphene-TMO semiconductor NP hybrids on the basis of their counterpart material oxide (from titanium to zinc) following the periodic table.

\section{Titanium dioxide $\left(\mathrm{TiO}_{2}\right)$-graphene hybrids}

Nanocrystalline $\mathrm{TiO}_{2}$ is an interesting material because of its unique optical and electrical properties. It has been used as a heterogeneous photocatalyst and it has outstanding advantages because of its low cost, scalability, nontoxicity, strong photooxidising power and stability in oxidative and acidic environments [78]. Extensive research on $\mathrm{TiO}_{2}$ nanomaterials has shown that the energy conversion efficiency of the photovoltaic devices that use $\mathrm{TiO}_{2}$ NPs critically depends on the morpholo- 
gy and size of the NPs $[79,80]$. Additionally, in $\mathrm{TiO}_{2}$-graphene hybrid systems, the morphology of $\mathrm{TiO}_{2}$ plays an important role in various applications.

$\mathrm{TiO}_{2}$ anode materials have outstanding cycling stability and almost no volume expansion occurs when $\mathrm{TiO}_{2}$ is fully lithiated. As the electrical conductivity of $\mathrm{TiO}_{2}$ is low, it has a weak rate capability in electrical devices. The modification of $\mathrm{TiO}_{2}$ with conductive materials like graphene improves its electrical performance significantly. The introduction of graphene into $\mathrm{TiO}_{2}$ results in increased conductivity of the hybrid material, higher transparency and efficient charge separation of the system which causes enhanced photocatalytic activity and other novel properties [81]. Also, due to its high conductivity, graphene is highly effective in improving the charge/discharge performance of $\mathrm{TiO}_{2}$ anodes and is responsible for the improved photocurrent response of the hybrid materials [82].

In most cases, for the formation of $\mathrm{TiO}_{2}$-graphene hybrids, $\mathrm{TiO}_{2}$ is prepared by hydrolysis of Ti-containing precursors [8385] as the hydrolysis rate of the Ti(IV) precursor is very rapid, even hydrolysed instantly when exposed to moisture, but it is not easy to control the morphology and structure of the as-prepared $\mathrm{TiO}_{2}$ NPs. The fabrication of $\mathrm{TiO}_{2}$-graphene hybrid systems results in a strong coupling between the components therefore resulting in superior activity as compared to the individual materials. The resultant hybrid material displays a synergistic effect of accumulated graphene and $\mathrm{TiO}_{2} \mathrm{NPs}$, exhibited by the extraordinary physical and chemical properties in comparison with pristine graphene and bare $\mathrm{TiO}_{2} \mathrm{NPs}[86,87]$.

Different synthesis routes have been introduced; among them, hydrothermal methods are used extensively for the preparation of $\mathrm{TiO}_{2}$-graphene hybrid systems. Liang et al. prepared $\mathrm{TiO}_{2}$ NCs on the GO sheet by hydrolysis methods and then converted GO to graphene by hydrothermal treatment [88]. A $\mathrm{TiO}_{2}$-graphene nanocomposite hydrogel (TGH) was prepared by Zhang et al. by a facile one-pot hydrothermal approach where the spherical nanostructured $\mathrm{TiO}_{2}$ NPs were densely decorated onto the GS [89].

A $2 \mathrm{D}$ graphene- $\mathrm{TiO}_{2}$ sandwich structure was prepared by using ethylenediamine $/ \mathrm{H}_{2} \mathrm{O}$ solvent in a reduction-hydrolysis technique. The photocatalytic activity of the hybrid has been confirmed by the conversion of $\mathrm{CO}_{2}$ to valuable hydrocarbons $\left(\mathrm{CH}_{4}\right.$ and $\left.\mathrm{C}_{2} \mathrm{H}_{6}\right)$ in water vapour (Figure 2 ). This opens the path for new significant applications of graphene for selectively catalytic $\mathrm{C}-\mathrm{C}$ coupling reaction [90]. Liu et al. have prepared $\mathrm{TiO}_{2}-$ graphene hybrid systems using a hydrothermal method. These hybrids have excellent electrochemical performance due to the synergetic effect of well-dispersed $\mathrm{TiO}_{2} \mathrm{NPs}$ and the conductive graphene network [91]. Nanometre-sized $\mathrm{TiO}_{2}$ sheets were prepared on the GSs by using a facial solvothermal synthetic route having improved photocatalytic properties due to the effective charge anti-recombination of graphene and the high catalytic activity of the facets [88].
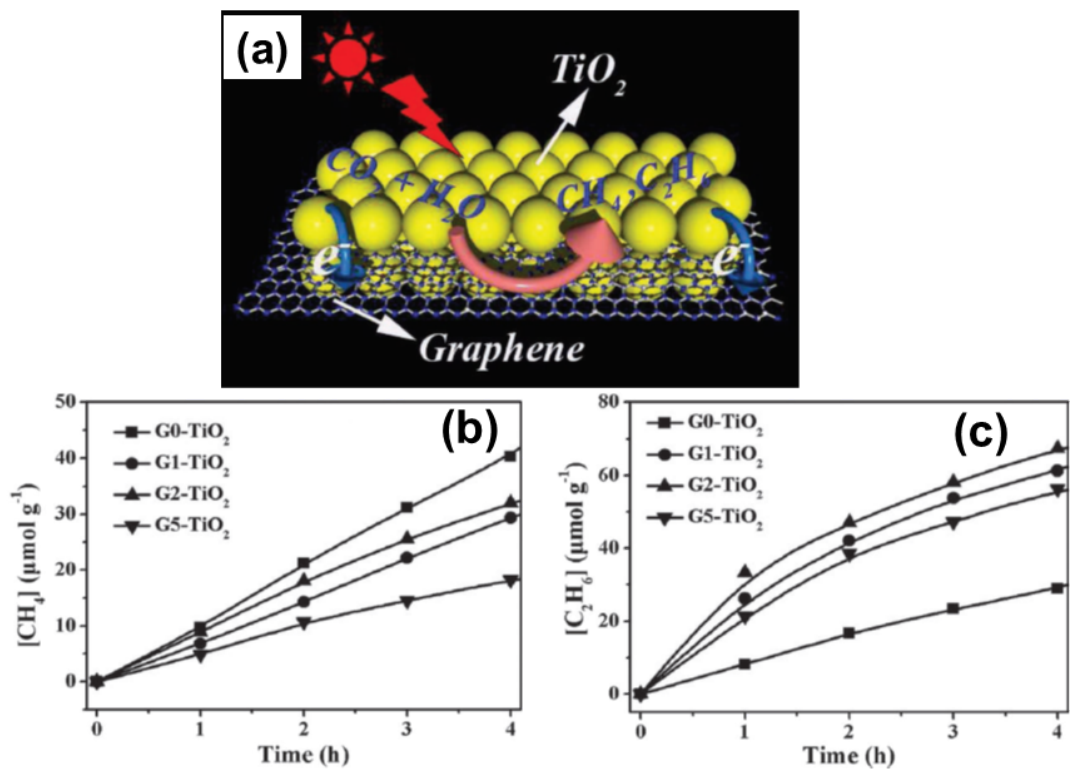

Figure 2: (a) Schematic illustration of the charge separation and transfer in the 2D sandwich-like graphene- $\mathrm{TiO}_{2}$ nanostructure system and photoreduction of $\mathrm{CO}_{2}$ into $\mathrm{CH}_{4}$ and $\mathrm{C}_{2} \mathrm{H}_{6}$. (b) Photocatalytic $\mathrm{CH}_{4}$ and (c) $\mathrm{C}_{2} \mathrm{H}_{6}$ evolution amounts for samples $\mathrm{G}_{x} \mathrm{TiO}_{2}(x=0,1,2,5)$. The weight contents of graphene designated as $x$ (wt \%). Reproduced with permission from [90], copyright 2013 Wiley-VCH Verlag GmbH \& Co. KGaA. 
An anionic surfactant-mediated growth of the self-assembled $\mathrm{TiO}_{2}$-graphene hybrid nanostructure synthesis was introduced by Wang et al., which shows enhanced Li-ion insertion/extraction kinetics in $\mathrm{TiO}_{2}$, especially at high charge/discharge rates [92]. When an inorganic layer has been intercalated between the two graphene layers it prevents the $\pi-\pi$ stacking, creating a functional separation between the individual GSs which allows a periodic modulation of the refractive index and interplay of photon and electron transport. Kumar Manga et al. have prepared multilayer thin films by a self-assembled layer-by-layer technique which consists of alternating titania $\left(\mathrm{Ti}_{0.91} \mathrm{O}_{2}\right)$ and GO nanosheets. The layer materials are spatially phase segregated to maintain unique $2 \mathrm{D}$ characteristics due to the functional separation of the layers at the nanoscale [93]. This hybrid system has potential for achieving the functional separation of charge transport and storage.

A highly efficient, stable, sandwich-structured $\mathrm{TiO}_{2}-\mathrm{Pt}-$ graphene hybrid has been prepared by Xia et al. where the graphene was synthesised by the arc discharge method and the Pt-graphene hybrid electrocatalysts were prepared using a polyol process. This structure exhibits enhanced electrochemical performance due to the strong metal-support interaction and proposed synergetic effect [94]. A molecular grafting process was employed in situ to incorporate $\mathrm{GSs}$ in $\mathrm{TiO}_{2}$ nanoparticle films for application in dye-sensitised solar cells. The conductivity of the film increases with the incorporation of the GSs, which in turn results in an enhancement of the power conversion efficiency [95].

A unique three dimensional (3D) nanostructure was fabricated by $\mathrm{Hu}$ et al. with nanometre-sized $\mathrm{TiO}_{2}$ intercalated between graphene layers as pillars which provide a 3D open space with distinct advantages when used as LIB anode materials [96]. (3-Aminopropyl)trithoxysilane was used to functionalise $\mathrm{TiO}_{2}$ NPs, and then the $\mathrm{TiO}_{2}$ NPs were wrapped by graphene. These hybrids have high potential for photocatalytic application [72]. Zhang et al. have reported graphene-encapsulated $\mathrm{TiO}_{2}$ nanospheres as efficient photocatalysts for the decomposition of rhodamine B with an efficiency up to $91 \%$ in $90 \mathrm{~min}$, which is much higher than the efficiency of $\mathrm{TiO}_{2}$ nanospheres $(65 \%)$ [97]. The graphene-based nanoarchitecture of $\mathrm{TiO}_{2}$ nanospindles [98], $\mathrm{TiO}_{2}$ nanorods [92] and $\mathrm{TiO}_{2}$ mesoporous [99] shows improved photocatalytic performance via structural optimisation of the architecture.

Although most of the applications of graphene- $\mathrm{TiO}_{2}$ make use of its photocatalytic activity, there are also some applications of shape-controlled $\mathrm{TiO}_{2}$-graphene hybrids used in pollutant abatement [100], high-performance anodes for microbial fuel cells [101], and self-cleaning applications [102].

\section{Vanadium oxide $\left(\mathrm{VO}, \mathrm{V}_{2} \mathrm{O}_{3}, \mathrm{VO}_{2}, \mathrm{~V}_{2} \mathrm{O}_{5}\right)$-graphene hybrids}

Vanadium has oxidation states ranging from -1 to +5 . Binary vanadium oxides have already been proven as a potential material for studying superconductivity at high pressures and lowdimensional quantum-spin transitions [103]. $\mathrm{VO}_{2}$ has two crystalline phases, monoclinic and rutile. The monoclinic form of vanadium(IV) oxide can be transferred to the rutile form by a thermally induced, reversible treatment at $68^{\circ} \mathrm{C}$ [104]. $\mathrm{VO}_{2}$ (M) behaves as a semiconductor whereas $\mathrm{VO}_{2}(\mathrm{R})$ behaves as a semimetal. Vanadium pentoxide $\left(\mathrm{V}_{2} \mathrm{O}_{5}\right)$ has very low electronic conductivity due to its low d-band mobility. It also shows a thermochromic transition at $257^{\circ} \mathrm{C}$ and this material is used as a catalyst for industrial processes, gas sensors and in LIBs [105]. Various nanostructures of $\mathrm{V}_{2} \mathrm{O}_{5}$ such as nanotubes, nanowires, nanofibers, nanobelts, and nanorods have been prepared by sol-gel processes, hydrothermal processes [106], electrochemical deposition, and reverse micelle transition [107]. Other vanadium oxides have been studied for their interesting phase change characteristics. Unlike the other oxides of vanadium, $\mathrm{VO}_{2}$ is quite stable during lithium intercalation-deintercalation cycles and has been regarded as a promising electrode material for both organic and aqueous LIB owing to high capacity, unique structure and suitable electrode potential. However, its cyclic performance is limited by its high charge-transfer resistance. The incorporation of graphene solves its electrical resistance problem with the $\mathrm{VO}_{2}$ electrodes and it acts as a high-performance electrochemical capacitor [108], shows enhanced optical response [109], and represents highly durable electrodes for $\mathrm{Li}$ and $\mathrm{Na}$ ion batteries [110].

Yang et al. have prepared $\mathrm{VO}_{2}$-graphene architectures by using graphene as a substrate for the in situ growth of $\mathrm{VO}_{2}$ ribbons (Figure 3a) via hydrothermal synthesis and chemical reduction of $\mathrm{V}_{2} \mathrm{O}_{5}$ by $\mathrm{GO}$ simultaneously in a Teflon lined autoclave
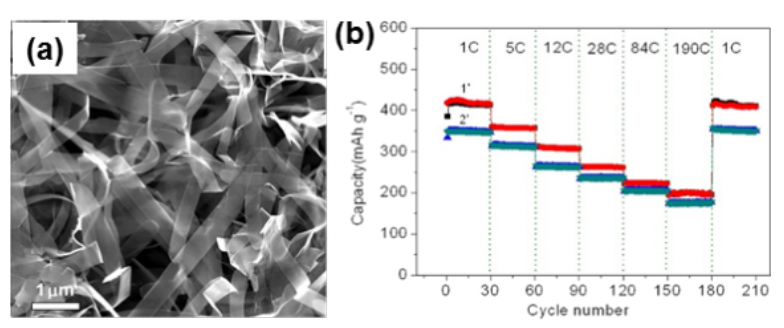

Figure 3: (a) Typical FE-SEM image of a $\mathrm{VO}_{2}$-graphene sample prepared by hydrothermal synthesis and reduction of a $\mathrm{V}_{2} \mathrm{O}_{5}$-graphite oxide composite for 1.5 and $12 \mathrm{~h}$ at $180^{\circ} \mathrm{C}$, demonstrating the formation of numerous ribbons with a width of $200-600 \mathrm{~nm}$ and length of several tens of micrometres. (b) Rate capacities of $\mathrm{VO}_{2}$-graphene architectures with different $\mathrm{VO}_{2}$ contents, measured for 30 cycles at each selected rate from 1 to 190 cycles. Reprinted (adapted) with permission from [111], copyright 2013 American Chemical Society. 
[111]. When this hybrid is used as a cathode material in LIBs, it provides fast charging and discharging capability with long cycle performance (Figure $3 \mathrm{~b}$ ). $\mathrm{VO}_{2}(\mathrm{M})$ nanotube-graphene hybrids cathode material is used in LIB, where the $\mathrm{VO}_{2}$ nanotubes are wrapped by and trapped between the GS [112]. Although the capacity of this hybrid is good, the rate capability is not.

To improve the rate capability, Nethravathi et al. use a hydrothermal method to prepare $\mathrm{N}$-doped graphene- $\mathrm{VO}_{2}$ nanosheetbuilt 3D flower hybrids [113], where this typical morphology results in a high surface area as well as better electrical contact with the graphene leading to better electrochemical performance. Liu et al. have developed a sol-gel method for the incorporation of GSs into $\mathrm{V}_{2} \mathrm{O}_{5}$ nanoribbons [114]. These sandwiched GSs not only show enhanced electrial conductivity but also preserve the water molecules between the two layers of $\mathrm{V}_{2} \mathrm{O}_{5}$ which facilitates the $\mathrm{Li}^{+}$diffusion, significantly improving the electrochemical performance. $\mathrm{V}_{2} \mathrm{O}_{5}$ quantum dot/ graphene is a promising cathode material for use in long-life rechargeable Li batteries $[115,116]$. Kim et al. have introduced the use of $\mathrm{VO}_{2}$-graphene hybrid materials for the fabrication of thermochromic films for energy saving windows. $\mathrm{VO}_{2}$ crystals have been prepared on graphene and the graphene-supported $\mathrm{VO}_{2}$ is easily transferred to a plastic substrate which enables formation of a new type of flexible thermochromic film [117]. This hybrid film exhibits efficient operation to reduce the in-house temperature under infrared irradiation.

\section{Chromium oxide $\left(\mathrm{Cr}_{2} \mathrm{O}_{3}\right)$-graphene hybrids}

$\mathrm{Cr}_{2} \mathrm{O}_{3}$, a trivalent chromium(III) oxide, is an important industrial material that has been used in abrading agents and pigments. Unlike other TMOs, $\mathrm{Cr}_{2} \mathrm{O}_{3}$ exhibits poor dispersion. It is insoluble in both acidic and alkaline media. The low electrical conductivity of $\mathrm{Cr}_{2} \mathrm{O}_{3}$ inhibits its application for practical use and electrical research fields. The poor dispersion results in a low surface area and a nonuniform porous structure which restricts its supercapacitive performance. Severe volume change happens for $\mathrm{Cr}_{2} \mathrm{O}_{3}$ during the charge-discharge cycles which results in a rapid capacity fading and the end of the cycle life.

Several strategies have been designed to increase the conductivity of the materials and also to improve the volume change. In that context, graphene has been hybridised with $\mathrm{Cr}_{2} \mathrm{O}_{3}$ to improve the properties of the materials and the other strategy is to develop $\mathrm{Cr}_{2} \mathrm{O}_{3}$ materials on the nanoscale. Graphene- $\mathrm{Cr}_{2} \mathrm{O}_{3}$ hybrids have been explored with respect to the oxygen reduction reaction (ORR) [118] and applications in energy storage [119]. ORR is the key step of renewable energy technologies including fuel cells and water splitting. For excellent electrocatalysts, one of the most important factors is long-term running stability. The long term running stability of the $\mathrm{Cr}_{2} \mathrm{O}_{3}-\mathrm{rGO}$ hybrid makes it a promising catalyst for fuel cells.

\section{Manganese oxide $\left(\mathrm{MnO}, \mathrm{Mn}_{2} \mathrm{O}_{3}, \mathrm{MnO}_{2}, \mathrm{Mn}_{3} \mathrm{O}_{4}\right.$, $\mathrm{Mn}_{2} \mathrm{O}_{7}$ )-graphene hybrids}

Pyrolusite $\left(\mathrm{MnO}_{2}\right)$, hausmanite $\left(\mathrm{Mn}_{3} \mathrm{O}_{4}\right)$ and bixbyite $\left(\mathrm{Mn}_{2} \mathrm{O}_{3}\right)$ are important minerals of manganese. These oxides have attracted great attention because of their environmental benignity and the high abundance of $\mathrm{Mn}$ in nature. Among all the oxides of manganese, $\mathrm{Mn}_{3} \mathrm{O}_{4}$ has been studied widely as an anode material for LIB to achieve higher specific capacities than graphite [120]. $\mathrm{Mn}_{3} \mathrm{O}_{4}$ has a spinal structure and is a potentially interesting electrode material as an electrolytic supercapacitor because of its low cost, environmental compatibility and intrinsically high capacity [18]. But compared to the other TMOs like $\mathrm{Co}_{3} \mathrm{O}_{4}$ and $\mathrm{Fe}_{3} \mathrm{O}_{4}, \mathrm{Mn}_{3} \mathrm{O}_{4}$ is a much less conductive material, so it is a great challenge to explore the $\mathrm{Mn}_{3} \mathrm{O}_{4}$ graphene hybrids in LIB applications. As a bulk material, $\mathrm{Mn}_{3} \mathrm{O}_{4}$ has low electrical conductivity that limits its ability in terms of both capacitance and capacitance retention at high current density. The most and widely used strategy is to combine $\mathrm{Mn}_{3} \mathrm{O}_{4}$ to lightweight and electronically conducting graphene. Graphene- $\mathrm{Mn}_{3} \mathrm{O}_{4}$ hybrids have also been employed as active, stable and low cost cathode electrocatalysts used for high capacity anode materials for LIBs [121-124]. The catalytic performance is associated with the morphology, size and coupling of the hybrid materials. Synergistic catalytic-supported interaction between $\mathrm{N}$-doped $\mathrm{rGO}$ and $\mathrm{Mn}_{2} \mathrm{O}_{4}$ is used for the vanadium redox flow batteries [125]. During cycling voltammetry, the almost insulating $\mathrm{Mn}_{3} \mathrm{O}_{4}$ is electrochemically oxidised to the more conductive $\mathrm{MnO}_{2}$. This explains the interesting phenomenon of increasing capacitance with cycling [126].

The $\mathrm{Mn}_{3} \mathrm{O}_{4}$-graphene hybrid has been also used for the ultrafast oxidative decomposition of methylene blue (MB) [127], for the catalytic decomposition of aqueous organics [128], for carbon dioxide adsorption [129], for ORR [130], for enhancing electrochemical performance for supercapacitors [131-133], and for catalytic oxidation and adsorption of elementary mercury [134]. Bag et al. have prepared $\mathrm{Mn}_{3} \mathrm{O}_{4}$ and $\mathrm{N}$-doped $\mathrm{rGO}$ which shows pronounced electrocatalytic activity towards ORR in alkaline solutions [135]. This hybrid can be prepared by different methods such as a two-step solution phase method (Figure 4a) [136], liquid phase deposition [137] or hydrothermal synthesis [138] for growing $\mathrm{Mn}_{3} \mathrm{O}_{4}$ NPs on the GO sheets. The $\mathrm{Mn}_{3} \mathrm{O}_{4}$-graphene hybrid is being explored for high capacity, low cost, nontoxic anode materials for battery applications (Figure 4b). $\mathrm{MnO}_{2}$ has a high theoretical capacity of $1232 \mathrm{mAh} \cdot \mathrm{g}^{-1}$ deduced from heterogeneous $\mathrm{Li}_{2} \mathrm{O}$ and $\mathrm{Mn}$ metal conversion reactions [139]. Yu et al. have prepared freestanding layer-by-layer assembled graphene- $\mathrm{MnO}_{2}$ hybrids by 

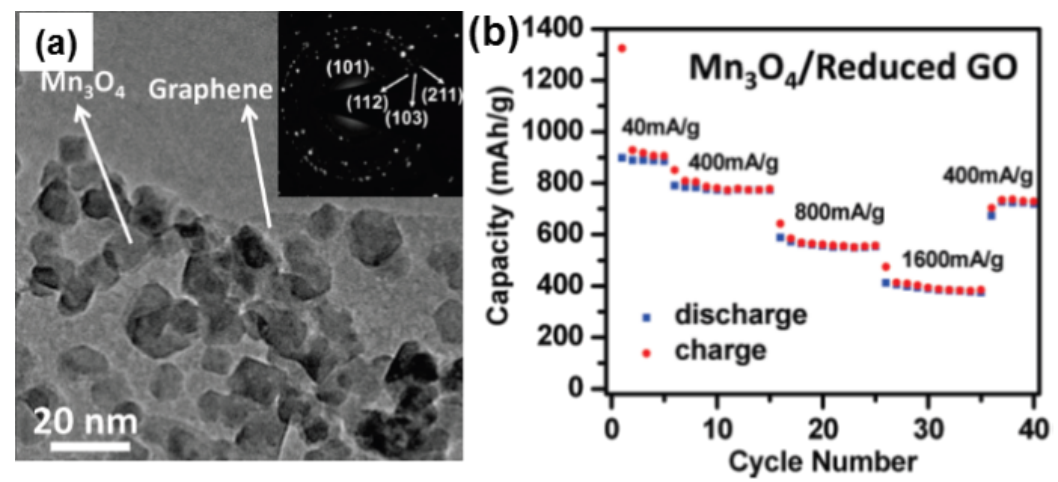

Figure 4: (a) TEM images of the $\mathrm{Mn}_{3} \mathrm{O}_{4}-\mathrm{rGO}$ hybrid; the inset shows the electron diffraction pattern of the $\mathrm{Mn}_{3} \mathrm{O}_{4} \mathrm{NPs}$ on rGO. (b) Capacity retention of the $\mathrm{Mn}_{3} \mathrm{O}_{4}$-graphene-hybrid-based anode at various current densities. Reprinted (adapted) with permission from [136], copyright 2010 American Chemical Society.

an ultrafiltration technique as an anode for LIBs [27]. Dong et al. have prepared 3D hybrids of $\mathrm{MnO}_{2}$ graphene foam where the morphology of the hybrids can be readily controlled by the solution acidity [139]. Ultrathin $2 \mathrm{D} \mathrm{MnO}_{2}$ graphene hybrids form high-performance flexible planar supercapacitors [140]. Graphene-wrapped $\mathrm{MnO}_{2}$ is also used for supercapacitor applications [141]. $\mathrm{MnO}$ has low conversion potential, low voltage hysteresis $(<0.8 \mathrm{~V})$, and high density $\left(5.43 \mathrm{~g} \cdot \mathrm{cm}^{-3}\right)$. The application of $\mathrm{MnO}$ in LIB is a great challenge because the low electric conductivity of $\mathrm{MnO}$ results in poor cycling stability and inferior rate capability. A long-term stable, nano-architecture of graphene-supported MnO NPs for LIB applications has been prepared by cycling where the oxidation of $\mathrm{Mn}$ (II) to $\mathrm{Mn}$ (III) and interfacial lithium storage upon cycling contribute to an enhanced specific capacity [142]. N-doped MnO-graphene prepared by a simple hydrothermal method followed by a heat treatment under ammonia atmosphere, shows a higher capacity and cycle life due to the unique $\mathrm{N}$-doped nanostructure and the efficient mixing with the conducting network [121].

\section{Iron oxide $\left(\mathrm{Fe}_{2} \mathrm{O}_{3}\right)$-graphene hybrids}

$\mathrm{Fe}_{2} \mathrm{O}_{3}$ has the advantages that it can be produced in high abundance, with low cost, and the nontoxicity of Fe results in a reduced environmental concern. Therefore, it is expected to meet the requirements of future energy storage systems. It is an attractive anode material for LIBs as it has a high theoretical capacity $\left(1007 \mathrm{mAh} \cdot \mathrm{g}^{-1}\right)$ [143] which is three times larger than that of graphite. During the cycling process, in the host matrix of $\mathrm{Fe}_{2} \mathrm{O}_{3}$ electrode pulverisation and rapid capacity decay happens due to the large specific volume change and particle aggregation. These obstacles can be removed by creating hybrids of $\mathrm{Fe}_{2} \mathrm{O}_{3}$ and graphene which have superior performance regarding flexibility and electrical conductivity [144] Most of the $\mathrm{Fe}_{2} \mathrm{O}_{3}$-graphene hybrids are prepared by hydrothermal methods without any reducing agent. Tian et al. have pre- pared $\alpha-\mathrm{Fe}_{2} \mathrm{O}_{3} \mathrm{NP}$ anchored graphene hybrid materials by hydrothermal methods which have good cycling performance and enhanced rate capability [145]. A 3D network of freestanding hollow $\mathrm{Fe}_{2} \mathrm{O}_{3}$-graphene has been fabricated by vacuum filtration and a thermal reduction process. This network shows superior electrical performance because the porous nature of the hybrid accommodates the volume change [146]. $\mathrm{Wu}$ et al. have use 3D N-doped graphene aerogel (GA) supported $\mathrm{Fe}_{3} \mathrm{O}_{4} \mathrm{NPs}\left(\mathrm{Fe}_{3} \mathrm{O}_{4} / \mathrm{N}-\mathrm{GA}\right)$ as efficient cathode catalysts for ORR [147]. This $\mathrm{Fe}_{3} \mathrm{O}_{4} / \mathrm{N}-\mathrm{GA}$ material shows excellent electrocatalytic activity for the ORR in alkaline electrodes. It is even larger than $\mathrm{N}$-doped carbon black or N-doped GSs (N-GSs) due to its 3D macroporous structure and high surface area, in addition to exhibiting a higher current density, lower ring current, lower $\mathrm{H}_{2} \mathrm{O}_{2}$ yield, higher electron transfer, and better durability (Figure 5). Chen et al. have prepared graphene/ $\gamma-\mathrm{Fe}_{2} \mathrm{O}_{3}$ hybrid aerogels for the first time which are used for biocatalytic transformation [148]. $\mathrm{Fe}_{2} \mathrm{O}_{3}$ supported on a $\mathrm{N}$-graphene hydrogel was prepared by a facial one-pot hydrothermal method by Ma et al. and is used as an advanced supercapacitor electrode material [149]. $\mathrm{Fe}_{2} \mathrm{O}_{3}$ graphene composites also have significant applications in LIBs [150-153]. Li et al. show the application of monolithic $\mathrm{Fe}_{2} \mathrm{O}_{3}$ graphene hybrids in arsenic removal also due to the self-supported adsorbent properties of the material [154]. $\alpha-\mathrm{Fe}_{2} \mathrm{O}_{3}-\mathrm{rGO}$ prepared by a hydrothermal method shows good catalytic performance towards the reduction of $\mathrm{H}_{2} \mathrm{O}_{2}$ [155]. Graphene- $\mathrm{Fe}_{3} \mathrm{O}_{4}$ spheres with diameter of about $100 \mathrm{~nm}$ were fabricated by a solvent-thermal route and this hybrid shows a homogeneous phase without obvious interface between graphene and $\mathrm{Fe}_{3} \mathrm{O}_{4}$ [156]. Yang et al. have fabricated porous iron oxide ribbons by controlling the nucleation and growth of iron precursors on a graphene surface, which was followed by an annealing treatment and used for high-performance lithium storage [157]. Liang et al. have prepared graphene- $\mathrm{Fe}_{3} \mathrm{O}_{4}$ NP hybrid paper by a filtration process 

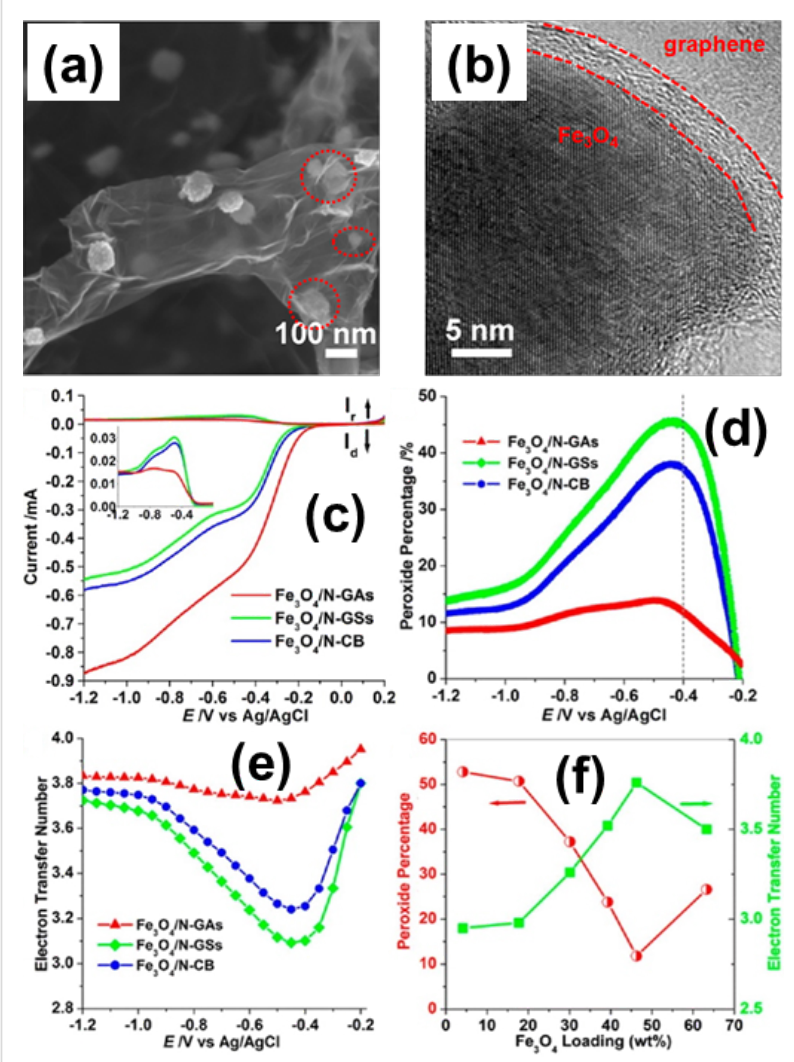

Figure 5: (a) SEM image of N-doped graphene aerogel (N-GA) supported $\mathrm{Fe} 3 \mathrm{O} 4 \mathrm{NPs}$ (Fe3O4/N-GA), where the red markings indicate $\mathrm{Fe}_{3} \mathrm{O}_{4} \mathrm{NPs}$ encapsulated in thin graphene layers. (b) HRTEM image of $\mathrm{Fe}_{3} \mathrm{O}_{4} / \mathrm{N}-\mathrm{GA}$, revealing an $\mathrm{Fe}_{3} \mathrm{O}_{4} \mathrm{NP}$ wrapped by graphene layers. (c) The rotating ring disk electrode (RRDE) test of the ORR on $\mathrm{Fe}_{3} \mathrm{O}_{4} /$ $\mathrm{N}$-GA, $\mathrm{Fe}_{3} \mathrm{O}_{4} / \mathrm{N}$-doped GS $\left(\mathrm{Fe}_{3} \mathrm{O}_{4} / \mathrm{N}\right.$-GSs), $\mathrm{Fe}_{3} \mathrm{O}_{4} / \mathrm{N}$-doped carbon black $\left(\mathrm{Fe}_{3} \mathrm{O}_{4} / \mathrm{N}-\mathrm{CB}\right)$ in an $\mathrm{O}_{2}$-saturated $0.1 \mathrm{M} \mathrm{KOH}$ electrolyte at a rotation rate of $1600 \mathrm{rpm}$. The inset shows the ring current as a function of the electrode potential. (d) Peroxide percentage and (e) electron transfer number of $\mathrm{Fe}_{3} \mathrm{O}_{4} / \mathrm{N}-\mathrm{GAs}, \mathrm{Fe}_{3} \mathrm{O}_{4} / \mathrm{N}-\mathrm{GSs}$, and $\mathrm{Fe}_{3} \mathrm{O}_{4} / \mathrm{N}-\mathrm{CB}$ as a function of the electrode potential. (f) Peroxide percentage and electron transfer number as a function of $\mathrm{Fe}_{3} \mathrm{O}_{4}$ loading at $-0.4 \mathrm{~V}$, as measured with $\mathrm{RRDE}$ in an $\mathrm{O}_{2}$-saturated $0.1 \mathrm{M} \mathrm{KOH}$ electrolyte. Reprinted (adapted) with permission from [147], copyright 2012 American Chemical Society.

which shows an actuation strain $56 \%$ higher than pristine graphene paper [158]. In another work, Liang et al. have prepared free-standing graphene- $\mathrm{Fe}_{3} \mathrm{O}_{4}$ hybrid papers having magnetic-controlled switching performance [159]. One interesting structure was realised using hydrothermal reduction by $\mathrm{Wu}$ et al. They prepared $\mathrm{Fe} @ \mathrm{Fe}_{2} \mathrm{O}_{3}$ core-shell NP-graphene hybrids which show good reversible lithium storage [160]. Another core-shell hollow nanomaterial, a $\gamma-\mathrm{Fe}_{2} \mathrm{O}_{3} @$ graphene hybrid, was prepared through the Kirkendall process by $\mathrm{Hu}$ et al. and showed high performance as an anode material for LIBs [161] The improved performance of the carbon-coated $\mathrm{Fe}_{2} \mathrm{O}_{3}$-graphene hybrids show that the improved performance in LIBs is attributed also to the carbon layer around the $\mathrm{Fe}_{2} \mathrm{O}_{3}$ NPs $[146,162]$. The thin carbon shells effectively inhibit the direct exposure of encapsulated $\mathrm{Fe}_{3} \mathrm{O}_{4}$ NPs to the electrolyte and preserve the structural and interfacial stabilisation of the NPs. The flexible and conductive graphene and carbon shell around the $\mathrm{Fe}_{3} \mathrm{O}_{4}$ NPs can accommodate the mechanical stress induced by the volume change of the NPs and thus maintain the structural and electrical integrity of the hybrid during the lithiation and delithiation processes [163]. Su et al. reported the change of dynamic behaviour and the conversion mechanism in LIBs by in situ transmission electron microscopy (TEM) characterisation [164].

$\mathrm{Fe}_{2} \mathrm{O}_{3}$ NPs showed volume expansion and morphological changes upon lithiation, and the surface of the electrode was covered by a $\mathrm{Li}_{2} \mathrm{O}$ layer. They also found that the single crystalline $\mathrm{Fe}_{2} \mathrm{O}_{3}$ NPs were converted to polycrystalline NPs and the delithiated product is no longer $\mathrm{Fe}_{2} \mathrm{O}_{3}$ but $\mathrm{FeO}$. A solvothermal process is introduced to construct $3 \mathrm{D}$ macroscopic $\mathrm{Fe}_{2} \mathrm{O}_{3}$ nanocube/N-doped graphene aerogels as an anode material for LIB applications [165]. This aerogel structure exhibits excellent rate capability and outstanding long-term cyclic stability at high current densities. Wang et al. have introduced a solvothermal-induced self-assembly approach to construct the monolithic 3D $\mathrm{Fe}_{2} \mathrm{O}_{3}$ and GS hybrids, which have excellent prolonged cycling stability [166]. Geng et al. have prepared $\mathrm{Fe}_{3} \mathrm{O}_{4}-\mathrm{rGO}$ hybrids by one-pot solution chemistry which have good adsorption capability of various dyes (rhodamine B, rhodamine $6 \mathrm{G}$, acid blue 92, orange (II), malachite green, and new coccine) [167]. These materials could be easily separated from the reaction medium due to the presence of the magnetic $\mathrm{Fe}_{2} \mathrm{O}_{3}$ NPs. In addition, the materials could be regenerated and utilised via a simple annealing treatment.

\section{Cobalt oxide $\left(\mathrm{CoO}, \mathrm{Co}_{2} \mathrm{O}_{3}, \mathrm{Co}_{3} \mathrm{O}_{4}\right)$-graphene hybrids}

Cobaltosic oxide $\left(\mathrm{Co}_{3} \mathrm{O}_{4}\right)$-graphene hybrids can be synthesised by solution methods. Like other hybrid TMO-graphene materials, this hybrid is also used as an anode for LIBs [168,169] because it exhibits high oxygen reduction activity. Liang et al. showed that $\mathrm{Co}_{3} \mathrm{O}_{4}-\mathrm{N}$-doped graphene exhibits similar catalytic activity like $\mathrm{Co}_{3} \mathrm{O}_{4}$-graphene hybrids but superior stability to Pt in alkaline solution [170] (Figure 6). N-doping of reduced mildly oxidised graphene oxide (rmGO) affords stronger coupling than rmGO and $\mathrm{Co}_{3} \mathrm{O}_{4}\left(\mathrm{Co}_{3} \mathrm{O}_{4} / \mathrm{N}-\mathrm{rmGO}\right.$ than in $\mathrm{Co}_{3} \mathrm{O}_{4} /$ rmGO) due to favourable nucleation and anchor sites for $\mathrm{Co}_{3} \mathrm{O}_{4}$ nanocrystals as N-groups help on rGO. In the ORR, the electronic effect of $\mathrm{N}$-doping of graphene also plays a role. Mao et al. have prepared 3D crumbled cobalt-GO nanostructure hybrids which show both ORR and oxygen evolution reaction (OER) [171]. Wu et al. have prepared 3D $\mathrm{Co}_{3} \mathrm{O}_{4} /$ flocculent graphene hybrids on $\mathrm{Ni}$ foam for supercapacitor applications as their nanocluster morphology synergistically results in an im- 

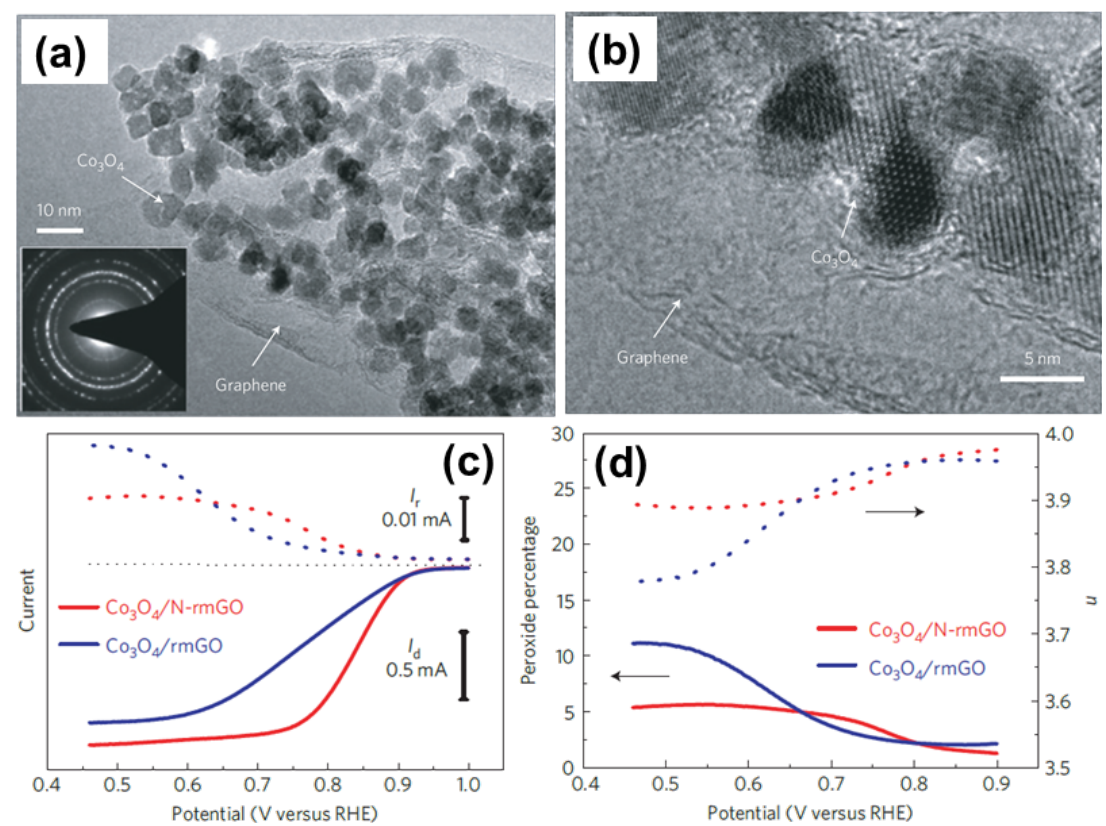

Figure 6: (a) Low magnification and (b) high magnification TEM images of $\mathrm{Co}_{3} \mathrm{O}_{4} / \mathrm{N}$-doped reduced mildly oxidised graphene oxide ( $\mathrm{N}$-rmGO) hybrid. (c) Assessment of peroxide percentage in ORR catalysed by hybrid catalysts was made from rotating ring-disk electrode voltammograms recorded with $\mathrm{Co}_{3} \mathrm{O}_{4} / \mathrm{rmGO}$ hybrids (loading $\approx 0.1 \mathrm{mg} \cdot \mathrm{cm}^{-2}$ ) and $\mathrm{Co}_{3} \mathrm{O}_{4} / \mathrm{N}-\mathrm{rmGO}$ hybrids (loading $\approx 0.1 \mathrm{mg} \cdot \mathrm{cm}^{-2}$ ) in $\mathrm{O}_{2}$-saturated $0.1 \mathrm{M} \mathrm{KOH}$ at $1,600 \mathrm{r}$.p. $\mathrm{m}$. Disk current $\left(I_{\mathrm{d}}\right)$ (solid line) is shown on the lower half and ring current $\left(I_{\mathrm{r}}\right)$ (dotted line) is shown on the upper half of the graph. The disk potential was scanned at $5 \mathrm{mV} \cdot \mathrm{s}^{-1}$ and the ring potential was constant at $1.5 \mathrm{~V}$ versus reversible hydrogen electrode (RHE). (d) Percentage of peroxide (solid line) and the electron transfer number $(n)$ (dotted line) of $\mathrm{Co}_{3} \mathrm{O}_{4} / \mathrm{rmGO}$ and $\mathrm{Co}_{3} \mathrm{O}_{4} / \mathrm{N}$-rmGO hybrids at various potentials, inferred from the corresponding RRDE data in (c). Reprinted by permission from [170], copyright 2011 Macmillan Publisher Ltd.

proved electrochemical performance [172]. Symmetric supercapacitors are based on $\mathrm{Co}_{3} \mathrm{O}_{4}$ NPs on vertically aligned graphene. This hybrid has also been used for nonenzymatic glucose detection in microdroplets [173].

Wang et al. fabricated graphene- $-\mathrm{Co}_{3} \mathrm{O}_{4}$ hybrid electrodes constructed on a micropipette tip which can detect nonenzymatic glucose [173]. N-doped graphene $/ \mathrm{Co}_{3} \mathrm{O}_{4}$ has been used for selective oxidation of olefins and alcohols [174], LIBs [175], and oxygen reduction [176], and as a water electrolysis catalyst [177]. $\mathrm{Co}_{3} \mathrm{O}_{4}$ NPs were anchored on conducting graphene and used as an anode for high-performance LIBs. This hybrid material exhibited large reversible capacity, excellent cyclic performance and good rate capability $[178,179]$. Magnetic cobalt NPs anchored on GSs were prepared by a two-step procedure, consisting of code position and thermal treatment [180]. The Co-graphene hybrid showed better catalytic performance as compared to Co only in the degradation of orange II. In another application, atomic cobalt on N-doped graphene has been used for hydrogen generation [181]. Singh et al. have prepared surface-tuned $\mathrm{Co}_{3} \mathrm{O}_{4}$ NPs on N-doped graphene by using a hydrothermal method [182]. Here, the N-doping plays an important role as a supporting material to ensure good dispersion of the oxide NPs and in bringing in favourable activity to the system. They show that this hybrid material reveals an ORR ac- tivity that is closely matched with the Pt-supported carbon catalyst in an alkaline medium. The $\mathrm{Co}_{3} \mathrm{O}_{4}$-graphene hybrid possesses catalytic performance for heterogeneous activation of peroxymonosulfate for the decomposition of phenol [183]. Moreover, the performance of the zinc-air battery (ZAB), fabricated by using this hybrid as the cathode, is found to be closely matched with the performance of the systems prepared with $\mathrm{Pt} /$ $\mathrm{C}$ cathodes. The activity enhancement of the system is due to multiple favourable factors, including the high roughness of $\mathrm{Co}_{3} \mathrm{O}_{4}$, homogeneous dispersion of the NPs, increased surface area of the catalyst, and most importantly, the synergetic interaction between the $\mathrm{N}$-doped graphene and $\mathrm{Co}_{3} \mathrm{O}_{4}$ NPs. In another work, Singh et al. have prepared three different morphologies of $\mathrm{Co}_{3} \mathrm{O}_{4}$ nanocubes, blunt edge nanocubes and spherical particles supported on N-doped graphene by a hydrothermal method [184]. Among those structures, the intermediate architecture, blunt edge nanocubes, show higher catalytic activity towards OER in alkaline medium. This is due to the presence of the low surface energy crystal plane of $\mathrm{Co}_{3} \mathrm{O}_{4} \mathrm{NPs}$ and their synergistic interaction between $\mathrm{N}$-doped because graphene helps to tune the properties of the OER electrocatalyst. Yang et al. fabricated graphene encapsulated $\mathrm{Co}_{3} \mathrm{O}_{4} \mathrm{NPs}$ which have a high reversible capacity of $1000 \mathrm{mAh} \cdot \mathrm{g}^{-1}$ over 130 cycles and is superior to $\mathrm{Co}_{3} \mathrm{O}_{4}$ NPs with respect to capacitor applications [185]. Kumar et al. have prepared graphene- 
wrapped $\mathrm{Co}_{3} \mathrm{O}_{4}$-intercalated hybrid nanostructures using microwave irradiation [186] and this hybrid shows cycling stability over 10,000 cycles.

$\mathrm{CoO}$ attracts extensive interest because of its high lithium storage capacity. CoO-NP-supported GSs effectively circumvent particle cracking, pulverisation, and aggregation upon cycling, thus serving as a high-performance anode material with long cycle life, high reversible specific capacity and excellent rate capability for LIB applications [187]. Self-assembled CoO nanorod clusters were synthesised on 3D graphene through a facile hydrothermal method followed by a heat treatment by Zhu et al. This hybrid exhibited good electromechanical performance [188]. Guo et al. prepared $\mathrm{Co} / \mathrm{CoO}$-graphene by selfassembly of Co NPs on the surface of graphene. This hybrid has similar activity as and better stability than commercial Pt NP catalyst supported on carbon (C-Pt) NPs and may serve as an alternative to $\mathrm{C}-\mathrm{Pt}$ catalysts for the ORR in alkaline solution [189]. Porous graphene wrapped CoO NPs show higher performance in OER due to the porous structure of the hybrid, resulting in high electroactive surface area as well as in strong chemical coupling between the components [190]. An electrochemical nonenzymatic sensor based on a $\mathrm{CoO}$-graphene hybrid is used for enzymeless glucose detection [191] and determination of carbofuran and carbaryl in fruits and vegetables [192]. Instead of using cobalt oxide-graphene hybrids, Yao et al. have synthesised a cobalt hydroxide nanoflake-rGO hybrid by a onepot hydrothermal method using glucose as a reducing agent for GO reduction [193]. This hybrid shows higher catalytic activity than $\mathrm{Co}(\mathrm{OH})_{2}$ for phenol degradation and it takes only $10 \mathrm{~min}$ for $100 \%$ phenol removal.

\section{Nickel oxide (NiO)-graphene hybrids}

$\mathrm{NiO}$, a p-type wide band gap semiconductor is extensively used as catalyst, battery cathode, electrochemical capacitor and magnetic material [194]. $\mathrm{NiO}$ is considered to be a promising alternative electrode material in redox electrochemical capacitors because of its easy synthesis and high capacitance. Porous NiO-rGO hybrid films were prepared by combination of electrophoretic deposition and chemical bath deposition methods $[195,196]$. Like other graphene-metaloxide hybrid systems, NiO-graphene hybrids are largely used for LIB applications [197-199]. Monolayer graphene/NiO nanosheet composite materials also have large application for supercapacitors [200-202] 3D NiO/ultrathin derived graphene hybrids show improved supercapacitor performance compared to bare $\mathrm{NiO}$ electrodes (Figure 7) [203]. The introduction of 3D ultrathin derived graphene and Ni foam scaffolds significantly increases the electron transfer rate and also the electrochemical activity of the reversible reaction of $\mathrm{Ni}^{\mathrm{II}}$ and $\mathrm{Ni}{ }^{\mathrm{III}}$. The $\mathrm{NiO}$-graphene hybrids show good sensing capability for the reducing gases such as $\mathrm{H}_{2}$,
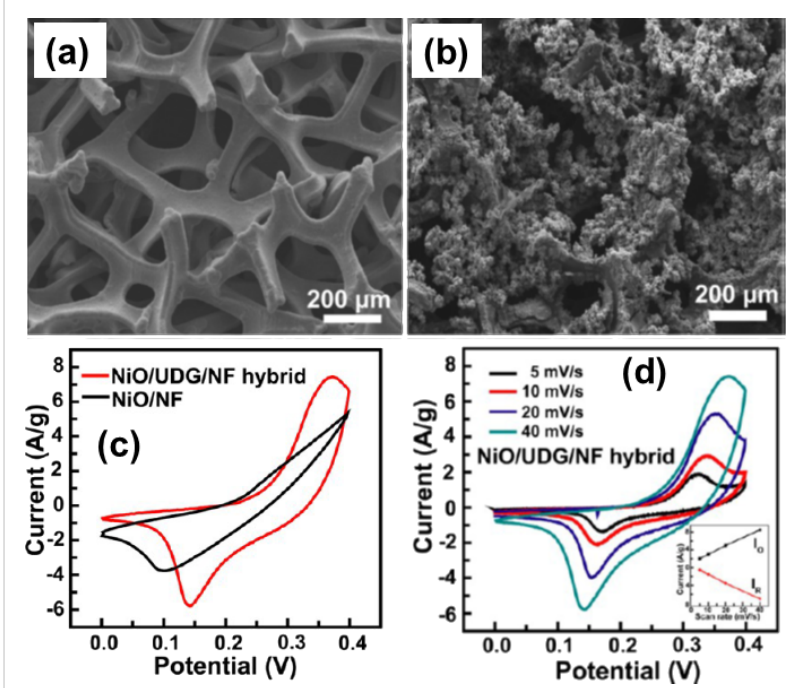

Figure 7: SEM images of (a) 3D ultrathin derived graphene/Ni foam (UDG/NF) scaffold and (b) NiO/UDG/NF hybrid after chemical bath deposition (CBD) growth of $\mathrm{NiO}$ nanoflakes. (c) Comparison of cyclic voltammograms of the NiO/UDG/NF hybrid and NiO/NF electrode at a scan rate of $40 \mathrm{mV} / \mathrm{s}$. (d) $\mathrm{CV}$ curves of the NiO/UDG/NF hybrid at different scan rates and linear response of the peak current intensity with the scan rate. Reprinted (adapted) with permission from [203], copyright 2014 American Chemical Society.

$\mathrm{NH}_{3}, \mathrm{H}_{2} \mathrm{~S}, \mathrm{NO}_{2}$ [204]. In another work graphene nanosheet-NiO hybrids in combination with DNA are used as the high-performance nonenzymatic glucose sensors [205]. Recently graphene-wrapped $\mathrm{NiO}$ hybrids were prepared by Kumar et al. for supercapacitor applications [206]. This hybrid can also be used as an electrochemical pseudocapacitor material for potential energy storage applications [207,208].

\section{Copper oxide $\left(\mathrm{Cu}_{2} \mathrm{O}, \mathrm{CuO}, \mathrm{CuO}_{2}\right.$, $\mathrm{Cu}_{2} \mathrm{O}_{3}$ )-graphene hybrids}

$\mathrm{Cu}$ nanowire (NW) films and indium tin oxide (ITO) films have comparable sheet resistances and optical transmittance. A few drawbacks of $\mathrm{Cu}$ NW films, such as low oxidation resistance or weak adhesion to the substrate, can be compensated for by the addition of graphene. The resulting hybrid films have improved electrical conductivity as they provide 2D pathways for charge transfer [209]. The graphene layer, acting as an oxidation resistance layer, fills the open space by a conductive and transparent film and it protects the NWs from the harsh environment [210].

$\mathrm{Cu}$ NW-graphene has been used as the back contact in thin film CdTe solar cells giving a solar efficiency of $12.1 \%$ with excellent thermal stability [209]. Cuprous oxide $\left(\mathrm{Cu}_{2} \mathrm{O}\right)$ is a p-type semiconductor and is used for solar energy conversion, as sensors and for photocatalytic degradation. The controlled synthesis of $\mathrm{Cu}_{2} \mathrm{O}$ results in a vast palette of architectures including nanocubes, nanocages, nanowires, solid and hollow spheres. 
Graphene-wrapped $\mathrm{Cu}_{2} \mathrm{O}$ nanocubes exhibit higher electrocatalytic performance towards electro-oxidation of glucose with lower detection time, and this hybrid has improved electrochemical stability [211]. Ding et al. have prepared $\mathrm{Cu}_{2} \mathrm{O}$ microspheres on rGO by a one-step synthesis which have potential application for nonenzymatic electrochemical glucose and $\mathrm{H}_{2} \mathrm{O}_{2}$ sensors [212]. Ortega-Amaya et al. synthesised GO-coated $\mathrm{Cu}_{2} \mathrm{O}$ and $\mathrm{Cu}$ NPs on copper foil by annealing at $200-1000{ }^{\circ} \mathrm{C}$ under an $\mathrm{Ar}$ atmosphere where the particle phase and particle size and shape strongly depend on the process temperature [213]. Deng et al. synthesised rGO-conjugated $\mathrm{Cu}_{2} \mathrm{O}$ NW mesocrystals by nonclassical crystallisation under hydrothermal conditions [214]. During the synthesis process, Ostwald ripening is responsible for the formation of the NW building block. This porous 3D framework structure, $\mathrm{Cu}_{2} \mathrm{O}$ NW-graphene hybrids, was used as a high-performance $\mathrm{NO}_{2}$ gas sensor (Figure 8). Copper oxide (CuO) is also a p-type semiconductor. $\mathrm{CuO}$-graphene composites have also been used as anode material for LIBs $[211,215]$. Mathesh et al. prepared GO hybrid materials consisting of $\mathrm{Cu}$ ions complexed with $\mathrm{GO}$, where $\mathrm{Cu}^{2+}$ acts as a bridge, connecting GO sheets and introducing new energy levels along the electron transport pathway thereby opening up possible conduction channels [216]. Singh et al. reported a bipolar, resistive switching device incorporating a copper oxide and multilayer graphene hybrid where the electrical characteristics of $\mathrm{CuO}$-graphene bilayer structure has been modified largely due to the electronic interaction at the hybrid interface. The $\mathrm{O}_{2}$ intake capacity of the multilayer
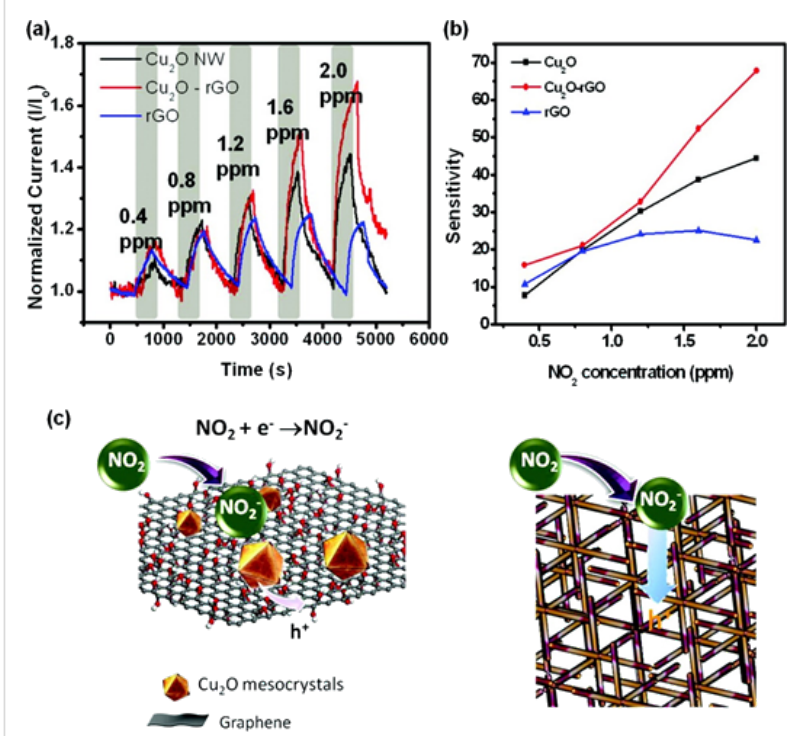

Figure 8: (a) Dynamic response of $\mathrm{Cu}_{2} \mathrm{O}$ NWs, $\mathrm{rGO}-\mathrm{Cu}_{2} \mathrm{O}$, and $\mathrm{rGO}$ devices under increasing $\mathrm{NO}_{2}$ exposure. (b) The sensitivity of the $\mathrm{NO}_{2}$ sensor for the three devices. (c) Schematic for the mechanism of $\mathrm{NO}_{2}$ sensing of $\mathrm{rGO}-\mathrm{Cu}_{2} \mathrm{O}$. Reprinted with permission from [214], copyright 2012 American Chemical Society. graphene results in reversible bipolar resistive switching properties [217]. Zhou et al. prepared graphene-wrapped $\mathrm{CuO}$ hybrids by a rapid, facile microwave-assisted hydrothermal method for LIB applications [218]. CuO-graphene nanostructures were used as nonenzymatic glucose sensors [219], humidity sensors [220], for $\mathrm{CO}_{2}$ mineralisation [221], as supercapacitors [222], and as pseudo-capacitor electrode materials [223].

\section{Zinc oxide ( $\mathrm{ZnO})$-graphene hybrids}

Most of the reports of graphene hybrid systems are related to $\mathrm{ZnO}$ NPs, as it is very easy to control the size and morphology of $\mathrm{ZnO}$ NPs as well as the properties of the material. $\mathrm{ZnO}$ is an important II-VI semiconductor with large direct band gap of $3.37 \mathrm{eV}$ and large exciton binding energy of $60 \mathrm{meV}$. It has been extensively studied because of its potential application in solar cells, sensors, diode lasers, piezoelectric devices, as surface acoustic wave propagators, antibacterial agents and ultraviolet light emitters. Graphene-based $\mathrm{ZnO}$ hybrids proved to be promising materials having a much wider range of applications in the field of energy conversion and storage, such as catalysts and in optoelectronics. Comprehensive work has been done to prepare graphene-wrapped ZnO NPs for better performance in optoelectronics applications. Single-layer graphene-wrapped ZnO NPs (Figure 9a) have been prepared by a facile technique by Son et al. They show varying electroluminescence spectra

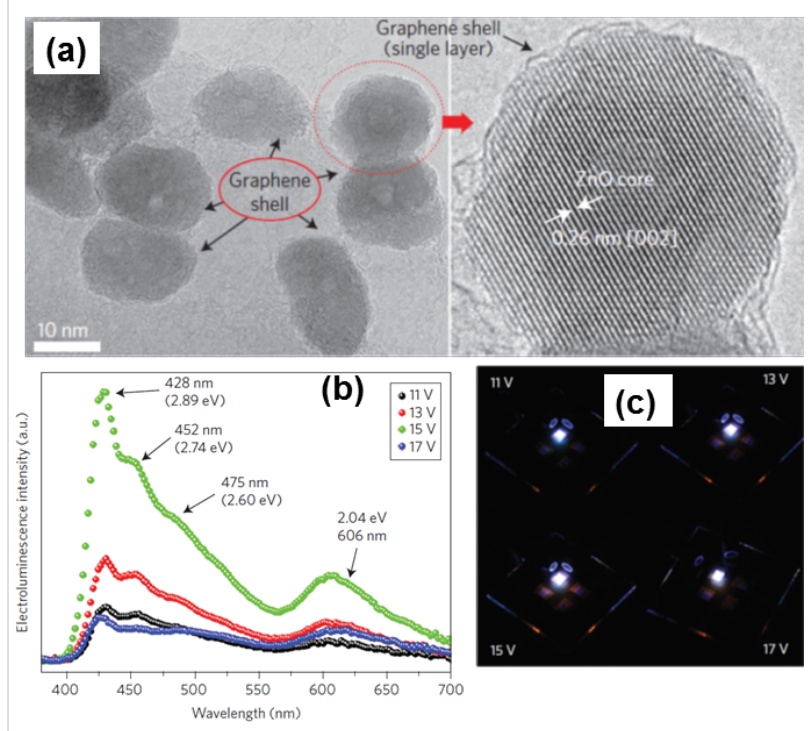

Figure 9: (a) High-resolution TEM images of $\mathrm{ZnO}$ quantum dots covered by graphene. The graphene shell layer of the $\mathrm{ZnO}$-core quantum dot covered by graphene looks like a single graphene layer. To the right, a magnified image shows the structure of the $\mathrm{ZnO}$ core and graphene monolayer. The $\mathrm{ZnO}$ petals grow along the [2] direction. (b) Electroluminescence spectra of the fabricated $\mathrm{ZnO}$-graphene quasi-quantum dot LED device with applied voltage from 11 to $17 \mathrm{~V}$. (c) Photograph of light emission at 11,13,15 and $17 \mathrm{~V}$ applied voltage bias, respectively. Reprinted by permission from [224], copyright 2012 Macmillan Publisher Ltd. 
with voltage (Figure 9b) which is used in white LEDs (Figure 9c) [224]. In this process, in the solution of di-methylformamide (DMF), $\mathrm{Zn}^{2+}$ is present along with $\mathrm{GO}$, where the $\mathrm{Zn}^{2+}$ reacts with the oxygen functional group of GO, leading to the formation of $\mathrm{Zn}-\mathrm{O}-\mathrm{C}$ bonds. During the reaction, sections of graphene detach from the GO through a layer-by-layer chemical peel-off process (chemical exfoliation) and partially encircle the ZnO NPs. The quasi-core-shell structure of the hybrid was prepared by a one-step chemical method [225].

For the formation of graphene-wrapped $\mathrm{ZnO}$ NPs, some other routes have been used, like chemical functionalisation of the $\mathrm{ZnO}$ surface. In this process there are three steps: surface modification of NPs mainly by amine groups, coating the NPs with a GO shell, and finally, conversion of GO to graphene by a reduction process. For the amine functionalisation of metal oxide NPs, poly(allylamine hydrochloride) (PAH) [226,227] and (3-aminopropyl)triethoxysilane [228-230] solution has been used widely. In this process, mostly the hydrothermal method has been utilised for the conversion of GO to graphene. Some $\mathrm{ZnO}$-graphene hybrids have been prepared by fabricating vertically aligned $\mathrm{ZnO}$ NWs on few or single layers of the graphene substrate. In most of the work, graphene has been prepared by a CVD process with a few layers and large area, whereas the $\mathrm{ZnO}$ nanostructures are synthesised on this graphene layer in a tube furnace [231], by hydrothermal methods [227,232-236], MOVPE [237,238], or electrochemical deposition [239]. Li et al. synthesised $\mathrm{ZnO}$-graphene hybrids by a facile freeze-drying treatment and a subsequent heat treatment method by using GO and a zinc hydroxide precursor [240]. In this process, $10 \mathrm{~nm}$ $\mathrm{ZnO}$ NPs are uniformly anchored on the N-doped graphene matrix to form the hybrid which has enhanced lithium storage capacity.

The optical properties of ZnO NPs change when they form hybrids with graphene. Pure $\mathrm{ZnO}$ exhibits a photoluminescence (PL) band at $373 \mathrm{~nm}$, which is due to the exciton recombination corresponding to the band edge emission, and a green emission peak is most commonly observed that arises from the defect of ZnO NPs such as oxygen vacancies, zinc vacancies, oxygen interstitials, and zinc interstitials [241]. Graphene does not show any photoluminescence emission peak as there is no band gap in its electronic state. On the other hand, the intensity of the PL for the band edge of $\mathrm{ZnO}$ decreases significantly in the hybrid, presumably due to the enhanced separation rate of photo-induced charge carriers by effective charge transfer from $\mathrm{ZnO}$ NPs to the conductive graphene layer [242-246]. The process of electron transfer is temperature dependent. The negative thermal quenching behaviour of $\mathrm{ZnO} \mathrm{NWs}$ and graphene shells was studied through charging and discharging processes between the two components, and it shows a higher quantum tunnelling probability between graphene and $\mathrm{ZnO}$ at an increased temperature [247]. ZnO-graphene quantum dot hybrid structures have potential for use as cathodes for field emission transition applications [248,249]. Kavitha et al. have prepared ZnO-rGO hybrids by a solution precipitation method and a hydrothermal method. The resulting structures show fluorescence quenching properties indicating the energy transfer between the components [250]. They also show that there is a 15 -fold enhancement in the nonlinear absorption coefficient of the $\mathrm{ZnO}-\mathrm{rGO}$ hybrid compared to the bare $\mathrm{ZnO}$. Once the electrons are transferred from $\mathrm{ZnO}$ NPs to graphene, they can be recirculated in the graphene channel within their lifetime. If the lifetime is long enough, the electrons form a system which can be utilised as highly sensitive light detectors or sensors $[251,252]$. Due to this synergetic effect via interfacial charge transfer and inhibition of recombination of excited electrons, this hybrid has wide spread applications in waste water purification by the photocatalytic degradation of dye molecules like MB [253-259], rhodamine B [260], and for the degradation of phenol [261]. This hybrid also has potential for the fabrication of biogas sensors and electrochemical sensors. The ZnO NPs decorated on graphene act not only as spacers between the GSs, but also to enhance the sensitivity towards common industrial toxin gases like $\mathrm{CO}, \mathrm{NH}_{3}$, $\mathrm{NO}$ [262], methane [263], $\mathrm{NO}_{2}$ [264], formaldehyde [265,266], $\mathrm{H}_{2}$ [267], and also to humidity [268]. Furthermore, this hybrid system is used for the photocatalytic reduction of $\mathrm{Cr}(\mathrm{VI})$ [269,270]. The introduction of a noble metal into the $\mathrm{ZnO}$-graphene hybrid produces a synergistic effect, which influences the electronic and chemical distribution of the materials, thereby favouring the adsorption of oxygen species and resulting in high-performance metal-oxidebased sensors. Silver-loaded hierarchical ZnO-rGO hybrids showed preferable detection of acetylene with specific response [271].

$\mathrm{ZnO}$ can be used as an inexpensive anode material and has high theoretical capacity $\left(978 \mathrm{mAh} \cdot \mathrm{g}^{-1}\right)$ but it has attracted less attention compared to the other metal oxides due to its poor cyclability resulting from huge volume change during charge-discharge cycles. Kushima et al. show that when $\mathrm{ZnO}$ NWs are partially lithiated, multiple cracks are induced and divided the NWs into multiple segments. This results in a lithium embrittlement effect in $\mathrm{ZnO}$ [272]. Such strain-induced cracking can be minimised by decreasing the particle size to the nanoscale. Sun et al. synthesised $\mathrm{ZnO}$ QDs of 2-7 nm on GSs by atomic layer deposition methods. They have enhanced the cycling stability and rate performance in LIBs [273]. $\mathrm{ZnO}$-graphene layered structures also showed improved cycling stability because the flexible graphene layer acts as a buffer to alleviate the volume change and as the separator to reduce the aggregation of the $\mathrm{ZnO}$ NPs [274]. 
Excellent performance in lithium storage capability is observed by incorporation of a conductive nitrogen-doped graphene matrix with $\mathrm{ZnO}$ due to a synergistic effect [240]. Boruah et al. used the thermal evaporation technique for the growth of highly dense $\mathrm{ZnO}$ nanowires on 3D graphene foam, which has potential application as ultraviolet photodetector [275]. $\mathrm{ZnO}$-graphene hybrids have been largely used for glucose sensing [276], hydrazine sensors [277], in antibacterial applications [278], in electrical and optical devices [279], as multifunctional conductors [280], for photocurrent generation [256], in solar cells [239,281,282], and for UV illumination [283].

\section{More than two component TMO-graphene hybrids}

Two TMOs can be hybridised with graphene for improved performance which increases the range of potential applications of the hybrid materials. Since the report of Padhi et al., the ironbased nanomaterial, olivine lithium iron phosphate $\left(\mathrm{LiFePO}_{4}\right)$, has attracted increasing attention because it is a promising candidate for cathode materials [284]. $\mathrm{LiFePO}_{4}$ is a promising cathode material for LIBs because of its high stability, high power, environmental safety, and low cost. However, the main drawback for $\mathrm{LiFePO}_{4}$ battery commercialisation is their poor rate performance (at current $>5 \mathrm{C}$ ) due to the low electrical conductivity and Li-ion diffusion rate which limits its usage for electrical applications. Those drawbacks are compensated for by hybridising $\mathrm{LiFePO}_{4}$ with graphene. Graphene-hybridised $\mathrm{LiFePO}_{4}$ has been largely used for LIBs [285-292]. The most interesting properties of $\mathrm{LiFePO}_{4}$ are mainly that the operating voltage and theoretical capacity can be increased by hybridisation with graphene. Shi et al. have prepared graphene-wrapped $\mathrm{Li}_{3} \mathrm{VO}_{4}$ microboxes by a one-step in situ hydrothermal method. This hollow structure could relax the stress and strain of $\mathrm{Li}^{+}$ insertion/extraction and provides extra space for the storage of $\mathrm{Li}$ ion. It also increases the surface area of the material, resulting in improved capacity, rate capability and cycling performance [293].

Much effort has been attributed to the development of Co-based anodes for LIB applications by partially replacing $\mathrm{Co}^{2+}$ in $\mathrm{Co}_{3} \mathrm{O}_{4}$ with more ecology friendly and inexpensive materials such as $\mathrm{Zn}, \mathrm{Cu}, \mathrm{Ni}, \mathrm{Mg}$, and $\mathrm{Fe}$. The substitution of environment friendly $\mathrm{Mn}^{2+}$ for toxic $\mathrm{Co}^{2+}$ in the $\mathrm{Co}_{3} \mathrm{O}_{4}$ spinal lattice results in the formation of $\mathrm{Co}(\mathrm{II}) \mathrm{Co}(\mathrm{III}) \mathrm{Mn}(\mathrm{III}) \mathrm{O}_{4}$. Hybridisation of this material with graphene results in further optimisation of catalytic properties. Wang et al. prepared a $\mathrm{MnCo}_{2} \mathrm{O}_{4}$-graphene hybrid by a two-step solution method by using $\mathrm{Co}(\mathrm{OAc})_{2}$ and $\mathrm{Mn}(\mathrm{OAc})_{2}$ precursors [294]. The hybrid was prepared by hydrolysing the precursors and GO coating followed by a solvothermal process. This hybrid shows improved catalytic properties. $\mathrm{MnCo}_{2} \mathrm{O}_{4}$-graphene has been used as a $\mathrm{LiO}_{2}$ battery cathode [295], an oxygen reduction electrocatalyst
[29], and in reducing fire hazards of poly(butylene terephthalate) [296]. Mohamed et al. have studied the influence of $\mathrm{Co}^{2+}$ replacement in the $\mathrm{Co}_{3} \mathrm{O}_{4}$ matrix by $\mathrm{M}^{2+}$ (where $\mathrm{M}=\mathrm{Mn}, \mathrm{Fe}$, $\mathrm{Ni}, \mathrm{Zn}$ ) for increasing the catalytic performance [297]. For the synthesis of the hybrid, they mainly use hydrothermal methods. Graphene- $\mathrm{ZnCo}_{2} \mathrm{O}_{4}$ hybrids have been used for the ORR [298]. Zhang et al. demonstrated graphene- $\mathrm{NiCo}_{2} \mathrm{O}_{4}$ hybrids as a methanol-tolerant electrocatalyst for the ORR with improved performance [299]. $\mathrm{NiCo}_{2} \mathrm{O}_{4}$-graphene has also been used in electrochemical pseudo-capacitor applications [300]. $\mathrm{NiCo}_{2} \mathrm{O}_{4}$ was anchored on the N-doped graphene prepared by a hydrothermal method, used for LIB applications, where the N-doping further improved the ORR performance in the $\mathrm{LiO}_{2}$ batteries [301]. Wu et al. prepared needle-like $\mathrm{NiCo}_{2} \mathrm{O}_{4}$ nanostructures on a $3 \mathrm{D}$ graphene foam with in situ deposition by a facile hydrothermal method which is used as an enzyme mimic for glucose and calcium detection [302]. $\mathrm{NiCo}_{2} \mathrm{O}_{4}$ nanoplatelets and graphene hybrids have been used for ORR and OER $[303,304]$.

Lee et al. shows that $\mathrm{NiCo}_{2} \mathrm{O}_{4}$ outperformed $\mathrm{Co}_{3} \mathrm{O}_{4}-$ graphene hybrids in terms of the onset potential and current densities. This property is attributed to the fact that the incorporation of Ni cations into the octahedral sites of the spinel crystal structure enhances the electrical conductivity as well as to the creation of new active sites with much lower activation energy [303]. 3D graphene not only increased the conductivity of $\mathrm{NiCo}_{2} \mathrm{O}_{4}$, but can also offer effective buffering to accommodate the lithiation-induced stress which is beneficial to lithium storage and cycling stability [305]. The $\mathrm{NiCo}_{2} \mathrm{O}_{4}-$ graphene is an attractive electrode material for supercapacitors [306,307]. $\mathrm{NiCo}_{2} \mathrm{~S}_{4}$-graphene hybrids synthesised by a one-pot solvothermal strategy are used for ORR and ORE [308]. Ning et al. prepared, for the first time, spinal $\mathrm{CuCo}_{2} \mathrm{O}_{4} \mathrm{NPs}$ on N-doped rGO. This was revealed to be an efficient electrocatalyst, produced by a two-step solvothermal method which exhibits ORR catalytic activity [309] (Figure 10). For the synthesis of the $\mathrm{CuCo}_{2} \mathrm{O}_{4} /$ $\mathrm{N}-\mathrm{rGO}$ hybrid, $\mathrm{GO}$ was reacted with $\mathrm{Co}(\mathrm{OAc})_{2}$ and $\mathrm{Cu}(\mathrm{OAc})_{2}$ in a 2:1 molar ratio at $80{ }^{\circ} \mathrm{C}$ in ethanol/water/ammonia, which led to the selective formation of the hybrid (Figure 10a). In this work, the detailed study shows that the $\mathrm{CuCo}_{2} \mathrm{O}_{4} / \mathrm{N}-\mathrm{rGO}$ hybrid exhibits higher ORR catalytic activity than the separated counterparts like $\mathrm{CuCo}_{2} \mathrm{O}_{4}$ or N-rGO, mixtures of $\mathrm{CuCo}_{2} \mathrm{O}_{4}$ and $\mathrm{N}-\mathrm{rGO}$ or $\mathrm{Co}_{3} \mathrm{O}_{4} / \mathrm{N}-\mathrm{rGO}$. The linear sweeping voltammograms (LSVs) of $\mathrm{CuCo}_{2} \mathrm{O}_{4} / \mathrm{N}-\mathrm{rGO}, \mathrm{Co}_{3} \mathrm{O}_{4} / \mathrm{N}-\mathrm{rGO}, \mathrm{CuCo}_{2} \mathrm{O}_{4}+$ $\mathrm{N}-\mathrm{rGO}, \mathrm{CuCo}_{2} \mathrm{O}_{4}$, and $\mathrm{N}-\mathrm{rGO}$ suggest that $\mathrm{CuCo}_{2} \mathrm{O}_{4} / \mathrm{N}-\mathrm{rGO}$ outperforms the other catalysts in terms of disk current density and half-wave potential in an $\mathrm{O}_{2}$-saturated $1 \mathrm{M} \mathrm{KOH}$ solution at a rotational rate of 1,600 rpm (Figure 10c). The hybrid gives an ORR peak at $-0.20 \mathrm{~V}$ in the $\mathrm{O}_{2}$-saturated solution at the $\mathrm{Pt} / \mathrm{C}$ electrode. The stability of the $\mathrm{CuCo}_{2} \mathrm{O}_{4} / \mathrm{N}-\mathrm{rGO}$ hybrid was 
tested and it was observed that the hybrid affords superior durability to the commercial $\mathrm{Pt} / \mathrm{C}$ catalyst.

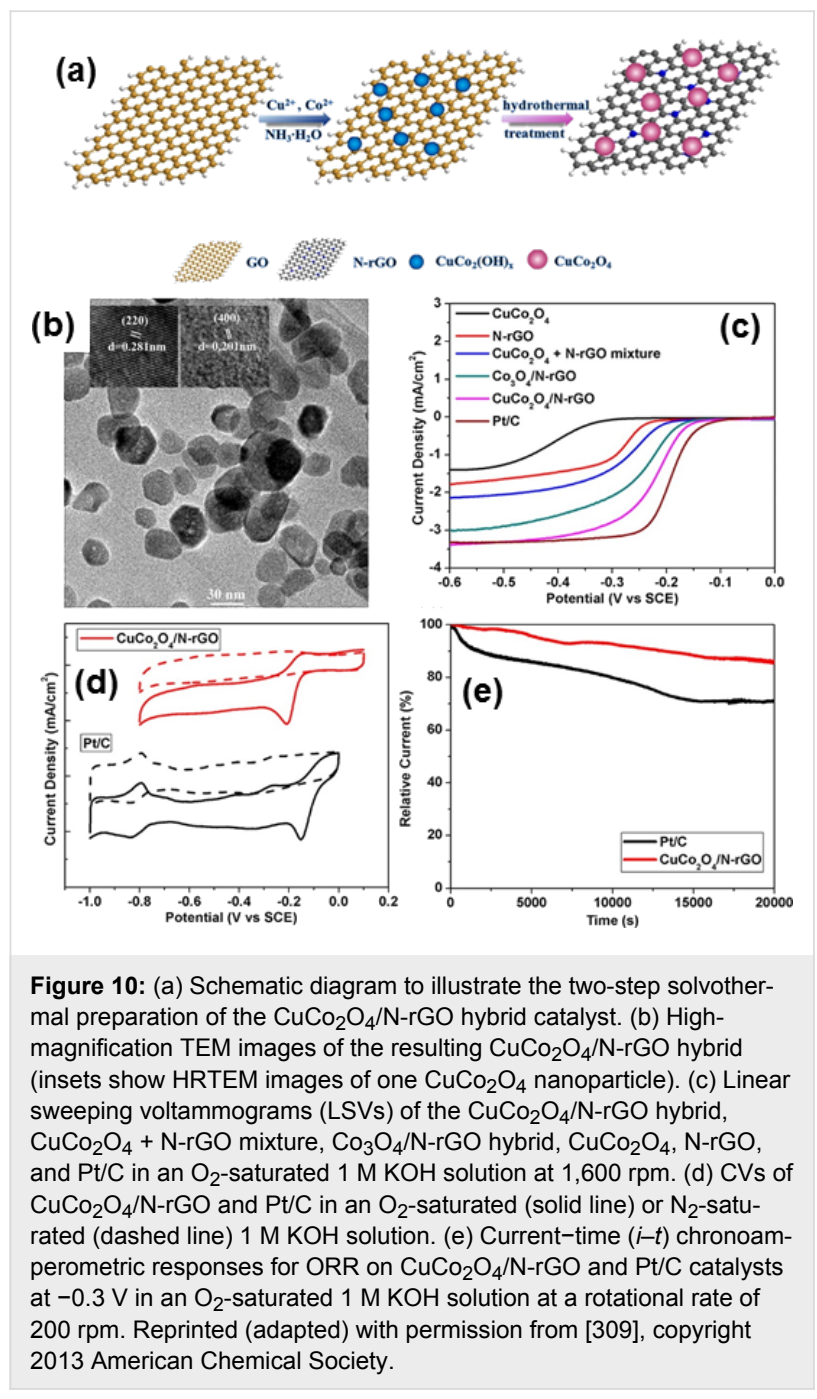

Over the past years another spinal-type ferrite having the general formula $\mathrm{MFe}_{2} \mathrm{O}_{4}(\mathrm{M}=\mathrm{Mn}, \mathrm{Fe}, \mathrm{Co}, \mathrm{Ni}, \mathrm{Cu})$ has attracted increased attention because of its large application as a catalyst. Spinal ferrites have interesting magnetic, magnetoresistive and magneto-optical properties. The high density magnetic storage is derived from the large surface area-to-volume ratio on the nanometre scale, and these materials have superparamagnetic behaviour. These spinal ferrites are considered to be promising anode materials for LIBs given their high specific capacity which is typically $2-3$ times higher than that of the graphite anode used in the commercial LIBs. Bai et al. have used a one-pot solvothermal method for the synthesis of $\mathrm{MFe}_{2} \mathrm{O}_{4}(\mathrm{M}=\mathrm{Mn}, \mathrm{Zn}, \mathrm{Co}, \mathrm{Ni})$ through the simultaneous reduction of $\mathrm{GO}$ and growth of $\mathrm{MFe}_{2} \mathrm{O}_{4}$ [310]. In this process, the size of the $\mathrm{MFe}_{2} \mathrm{O}_{4}$ microsphere can be controlled by adjusting the metal ion concentration. This hybrid displays a large adsorp- tion capacity and photocatalytic activity towards RhB and MB and can be easily separated by a magnet. Among all the ferrites of the form $\mathrm{MFe}_{2} \mathrm{O}_{4}(\mathrm{M}=\mathrm{Mn}, \mathrm{Fe}, \mathrm{Co}, \mathrm{Ni}, \mathrm{Cu})$, manganese ferrite $\left(\mathrm{MnFe}_{2} \mathrm{O}_{4}\right)$ has been found to exhibit usually large capacitance. A $\mathrm{MnFe}_{2} \mathrm{O}_{4}-\mathrm{rGO}$ hybrid which shows higher catalytic performance than pure $\mathrm{MnFe}_{2} \mathrm{O}_{4}$ to activate peroxymonosulfate (PMS) to various oxidatively degraded organic pollutants in water, has been prepared by a facile approach [311].

Cai et al. have synthesised $\mathrm{MnFe}_{2} \mathrm{O}_{4}$-graphene hybrids by immobilising the $\mathrm{MnFe}_{2} \mathrm{O}_{4}$ microspheres on the graphene nanosheets by a solvothermal route for supercapacitance application [312]. This hybrid is also used for the purification of contaminated water by removal of glyphosate [313] and efficient removal of arsenic from water [314]. $\mathrm{GO}-\mathrm{MnFe}_{2} \mathrm{O}_{4}$ nanohybrids are used for removal of lead and arsenic from water [314].

Another material in the family of spinal-type ferrites is magnetic cobalt ferrite $\left(\mathrm{CoFe}_{2} \mathrm{O}_{4}\right)$ which was proposed for biomedical applications. The hybrid material shows good magnetism and could be separated from the solution by using a magnet. This hybrid has been prepared by a solvothermal method, a facial vapour diffusion method [315], and by a hydrothermal method [316]. $\mathrm{CoFe}_{2} \mathrm{O}_{4}$-graphene hybrids show improved electrochemical properties and are used as binder-free anode materials for LIBs [317-319]. Yao et al. have prepared $\mathrm{CoFe}_{2} \mathrm{O}_{4}-$ graphene hybrids by chemical precipitation of $\mathrm{Fe}$ and $\mathrm{Co}$ precursors and reduction of GO in a hydrazine hydrate solution; this hybrid has been used for the degradation of phenol [320].

$\mathrm{Li}$ et al. prepared graphene-functionalised $\mathrm{CoFe}_{2} \mathrm{O}_{4}$ by a facile hydrothermal method using inorganic salts with the thermal exfoliation of GSs. This hybrid is an effective absorbent for removing methyl orange from water [321]. Yao et al. prepared $\mathrm{CoFe}_{2} \mathrm{O}_{4}$-graphene hybrid materials by in situ chemical deposition and a reduction process which have catalytic performance in the heterogeneous activation of peroxymonosulfate (PMS) of phenol [320] (Figure 11).

A nitrogen absorption isotherm was used to estimate the pore size of the hybrid to be about $1.7-5.9 \mathrm{~nm}$. The catalytic study of the $\mathrm{Co}_{2} \mathrm{Fe}_{2} \mathrm{O}_{4}$-graphene hybrid shows that the hybrid shows better catalytic activity than pure $\mathrm{CoFe}_{2} \mathrm{O}_{4}$ (Figure 11b). The $\mathrm{Co}_{2} \mathrm{Fe}_{2} \mathrm{O}_{4}$-graphene hybrids can be easily removed from the reaction solution by applying an external magnetic field (Figure 11c). $\mathrm{CoFe}_{2} \mathrm{O}_{4}$-graphene hybrids are used for photodegradation of MB [322,323], degradation of plasticizers [324] and the decomposition of phenol [320,325]. This material is also used as an absorbing material [315]. The bicomponent $\mathrm{CoO} / \mathrm{CoFe}_{2} \mathrm{O}_{4}$ hybridised with $\mathrm{N}$-doped graphene provides a simple and efficient way to configure hybridised electrode ma- 

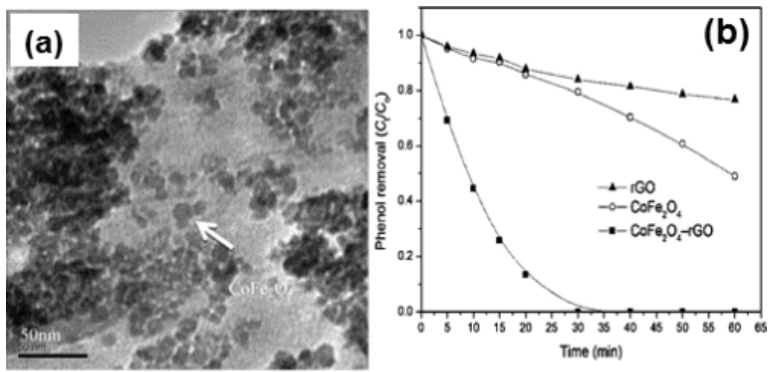

(c) (i)

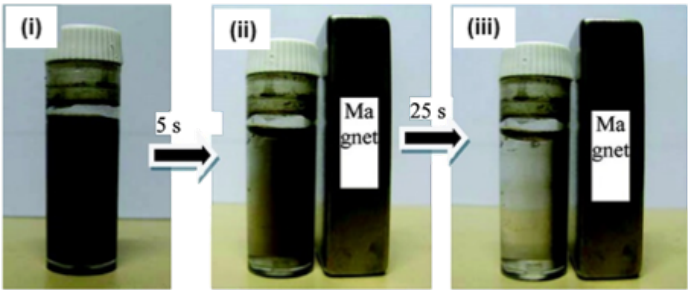

Figure 11: (a) TEM image of $\mathrm{CoFe}_{2} \mathrm{O}_{4}-\mathrm{rGO}$ hybrid. (b) Phenol degradation using $\mathrm{CoFe}_{2} \mathrm{O}_{4}-\mathrm{rGO} / \mathrm{PMS}$ (reaction conditions:

[phenol] $=20 \mathrm{mg} / \mathrm{L},[\mathrm{PMS}]=0.3 \mathrm{~g} / 150 \mathrm{~mL}$, [catalyst] $=10 \mathrm{mg} / 150 \mathrm{~mL}$ ) (c) Photographs of the separation and redispersion processes of $\mathrm{CoFe}_{2} \mathrm{O}_{4}-\mathrm{rGO}$ : (i) without external magnetic field, and (ii, iii) with external magnetic field. Reprinted (adapted) with permission from [320], copyright 2012 American Chemical Society.

terials with high lithium storage capacity [326]. The authors used a one-step hydrothermal method followed by annealing for the successful fabrication of the bicomponent $\mathrm{CoO} / \mathrm{CoFe}_{2} \mathrm{O}_{4}$. Furthermore, this hybrid has been used for microwave absorption applications and as electromagnetic wave absorbers [327]. Li et al. developed a facile one-pot polyol strategy to fabricate sandwich structures of graphene nanosheets decorated with $\mathrm{CoFe}_{2} \mathrm{O}_{4}$ superparamagnetic NCs [327]. The enhancement of the electromagnetic wave absorption properties of $\mathrm{CoFe}_{2} \mathrm{O}_{4}$ by the introduction of graphene is due to the synergistic effect between the remarkable magnetic loss from the superparamagnetic $\mathrm{CoFe}_{2} \mathrm{O}_{4}$ nanocrystals and high electric loss from the lightweight graphene. For LIB applications, graphenehybridised $\mathrm{CoFe}_{2} \mathrm{O}_{4}$ [318] and $\mathrm{Co}_{3} \mathrm{Sn}_{2} @ \mathrm{Co}$ [328] have been widely used.

$\mathrm{ZnFe}_{2} \mathrm{O}_{4}$ is an important, promising anode candidate for LIB applications due to its low discharge potential and high theoretical specific capacity of $1072 \mathrm{mAh} \cdot \mathrm{g}^{-1}$ [329]. The $\mathrm{ZnFe}_{2} \mathrm{O}_{4}$ graphene hybrid films are directly usable anodes for rechargeable lithium half-cells without adding any polymer or conductive additives [330]. $\mathrm{ZnFe}_{2} \mathrm{O}_{4}$ is a magnetic semiconductor material, thus $\mathrm{ZnFe}_{2} \mathrm{O}_{4}$-based catalysts can be magnetically separated in the suspension system. $\mathrm{ZnFe}_{2} \mathrm{O}_{4}$-graphene hybrids prepared by the hydrothermal method show higher catalytic performance [331,332]. The improvement of the catalytic performance of the hybrid is due to the fast photogenerated charge separation and transfer due to the high electron mobility of GSs, larger light absorption, and high specific surface area of the hybrid [332]. Song et al. have prepared a $\mathrm{ZnFe}_{2} \mathrm{O}_{4}$-graphene hybrid by a self-assembly method for application in LIBs [333]. The hybrid acts as a catalyst for decolourisation of various dyes, elimination of the organic pollutant under visible light irradiation, and the magnetic properties of the sample helps for the easy separation from the solution [334].

In summary, graphene-TMO NPs hybrids have received particular attention because of their unique properties. Due to the advantageous properties of these graphene-TMO hybrids, they have wide-spread application potential as photocatalysts, anode materials in LIBs, solar cells, sensors, diodes and also for the removal of organic pollutants from water (Figure 12).

Figure 12: Different potential applications of graphene-TMO hybrid materials.

A multitude of synthesis methods have been introduced by different research groups for the synthesis of the hybrids, among those, hydrothermal methods, sol-gel processes, chemical synthesis, and microwave-assisted growth have drawn the most attention in top-down approaches, while in bottom-up approaches, CVD and arc discharge methods have been mostly used. Depending on the application need, hybrids with different structures have been prepared by selecting the appropriate synthesis process (Table 1).

\section{Conclusion}

Since the first experimental demonstration of single sheet graphene in 2004, the field of graphene-related research has grown at an outstanding speed. Graphene has a unique morphology, large surface area, and extraordinary electronic properties. Graphene has been synthesised by various methods and its chemical structure can be modified by changing the fabrication methods and also by combining with various NPs. Such materials are produced to meet the increasing demands of high-performance materials in electronic devices. 
Enhanced knowledge on the surface chemistry and functionalisation of the graphene surface, and also on the improvement in the colloidal synthesis of NPs, will lead to a wide range of potential applications related to the preparation of graphene-NPs hybrid materials by the incorporation of various NPs. The synthesis of graphene-based composites also requires a

Table 1: Important hybrid material synthesis procedures and their potential applications.

\begin{tabular}{|c|c|c|c|c|}
\hline Hybrid material & Synthesis procedure & Applications & Structure & Ref. \\
\hline \multirow[t]{13}{*}{$\mathrm{TiO}_{2}$-graphene } & solvothermal process & photocatalytic activity & NPs on GS & [335] \\
\hline & self-assembly & $\begin{array}{l}\text { photocatalytic and } \\
\text { electrochemical activity }\end{array}$ & 3D hydrogel & [89] \\
\hline & & LIBs & NPs & {$[92,98]$} \\
\hline & hydrothermal process & photocatalytic activity & graphene-wrapped NPs & [72] \\
\hline & & DSSCs & NPs on GS & [87] \\
\hline & chemical synthesis & LIBs & paper & {$[96]$} \\
\hline & & self-cleaning application & $\begin{array}{l}\text { graphene-loaded thin } \\
\text { film }\end{array}$ & {$[102]$} \\
\hline & calcination process & photocatalytic activity & $\begin{array}{l}\text { graphene-encapsulated } \\
\text { hollow nanospheres }\end{array}$ & {$[97]$} \\
\hline & $\begin{array}{l}\text { microwave-assisted } \\
\text { technique }\end{array}$ & supercapacitors & NPs & {$[86]$} \\
\hline & $\begin{array}{l}\text { reduction-hydrolysis } \\
\text { technique }\end{array}$ & photocatalytic activity & sandwich & {$[90]$} \\
\hline & $\begin{array}{l}\text { molecular grafting } \\
\text { process }\end{array}$ & DSSCs & $\begin{array}{l}\text { graphene incorporated } \\
\text { in NP films }\end{array}$ & [95] \\
\hline & electrostatic deposition & $\begin{array}{l}\text { photoconversion } \\
\text { properties }\end{array}$ & multilayer films & [93] \\
\hline & $\begin{array}{l}\text { microwave-assisted } \\
\text { solvothermal process }\end{array}$ & fuel cells & NPs & {$[101]$} \\
\hline \multirow[t]{6}{*}{$\mathrm{VO}_{2}$-graphene } & chemical synthesis & LIBs & ribbons & {$[111]$} \\
\hline & layer-by-layer process & $\begin{array}{l}\text { enhanced optical } \\
\text { response }\end{array}$ & films & {$[109]$} \\
\hline & $\begin{array}{l}\text { CVD/Magnetron } \\
\text { sputtering }\end{array}$ & $\begin{array}{l}\text { flexible thermochomic } \\
\text { window }\end{array}$ & films & {$[117]$} \\
\hline & chemical synthesis & LIBs & graphene-coated NPs & {$[110,112]$} \\
\hline & hydrothermal process & $\begin{array}{l}\text { electrochemical } \\
\text { capacitor }\end{array}$ & NPs & {$[108]$} \\
\hline & & LIBs & nanotube/graphene & [113] \\
\hline \multirow[t]{4}{*}{$\mathrm{V}_{2} \mathrm{O}_{5}$-graphene } & sol-gel process & LIBs & $\begin{array}{l}\text { incorporation of GS in } \\
\text { nanoribbons }\end{array}$ & {$[114]$} \\
\hline & solvothermal process & LIBs & porous NPs & [116] \\
\hline & self-assembly process & LIBs & $\begin{array}{l}\text { hollow microspheres, } \\
\text { nanorods }\end{array}$ & {$[107]$} \\
\hline & $\begin{array}{l}\text { solution-phase } \\
\text { synthesis }\end{array}$ & LIBs & NPs & {$[115]$} \\
\hline \multirow[t]{2}{*}{$\mathrm{Cr}_{2} \mathrm{O}_{3}$-graphene } & $\begin{array}{l}\text { pyrolysis of } \\
\text { chromium/urea } \\
\text { coordinated compound }\end{array}$ & catalyst (ORR) & rGO-supported NPs & {$[118]$} \\
\hline & chemical synthesis & capacitance & NP-decorated rGO & [119] \\
\hline \multirow[t]{5}{*}{$\mathrm{MnO}_{2}$-graphene } & self-assembly & supercapacitors & $\begin{array}{l}\text { graphene-wrapped } \\
\text { honeycomb NPs }\end{array}$ & {$[141]$} \\
\hline & layer-by-layer assembly & LIBs & thin films & [27] \\
\hline & $\begin{array}{l}\text { modified Hummers } \\
\text { method and glucose } \\
\text { reduction }\end{array}$ & $\begin{array}{l}\text { oxidative decomposition } \\
\text { of } \mathrm{MB}\end{array}$ & NPs & {$[127]$} \\
\hline & $\begin{array}{l}\text { vacuum filtration } \\
\text { process }\end{array}$ & flexible supercapacitor & $\begin{array}{l}\text { quasi-2D ultrathin } \\
\text { nanosheet }\end{array}$ & {$[140]$} \\
\hline & chemical synthesis & supercapacitor & foams & [139] \\
\hline
\end{tabular}


Table 1: Important hybrid material synthesis procedures and their potential applications. (continued)

\begin{tabular}{|c|c|c|c|c|}
\hline \multirow[t]{15}{*}{$\mathrm{Mn}_{3} \mathrm{O}_{4}$-graphene } & \multirow[t]{4}{*}{ hydrothermal process } & supercapacitor & nanorods on GS & [138] \\
\hline & & supercapacitor & NP anchored rGO & [126] \\
\hline & & $\begin{array}{l}\text { carbon dioxide } \\
\text { adsorption }\end{array}$ & porous material & [129] \\
\hline & & LIBs & NPs & [124] \\
\hline & $\begin{array}{l}\text { hydrothermal } \\
\text { self-assembly method }\end{array}$ & supercapacitor & 3D network & [131] \\
\hline & \multirow[t]{3}{*}{ chemical synthesis } & catalyst (ORR) & NPs & {$[135]$} \\
\hline & & LIBs & NPs on rGO & {$[120,136,137]$} \\
\hline & & $\begin{array}{l}\text { catalyst (decomposition } \\
\text { of organic pollutants) }\end{array}$ & NPs & {$[128]$} \\
\hline & gel-like film synthesis & LIBs & film & [122] \\
\hline & $\begin{array}{l}\text { ion exchange followed } \\
\text { by calcination }\end{array}$ & capacitance & $\begin{array}{l}\text { NPs distributed on the } \\
\text { surface of rGO }\end{array}$ & [133] \\
\hline & $\begin{array}{l}\text { two-step liquid phase } \\
\text { procedure }\end{array}$ & LIBs & $\begin{array}{l}\text { NPs integrated with } \\
\text { graphene }\end{array}$ & [130] \\
\hline & $\begin{array}{l}\text { deposition/precipitation } \\
\text { method }\end{array}$ & $\begin{array}{l}\text { elemental mercury } \\
\text { capture }\end{array}$ & NPs & [134] \\
\hline & $\begin{array}{l}\text { ultrasound-assisted } \\
\text { synthesis }\end{array}$ & LIBs & nanosheets & [123] \\
\hline & $\begin{array}{l}\text { gel formation and } \\
\text { electrochemical } \\
\text { reduction }\end{array}$ & $\begin{array}{l}\text { electrochemical } \\
\text { properties }\end{array}$ & paper & [132] \\
\hline & chemical synthesis & $\begin{array}{l}\text { electrocatalysts for } \\
\text { vanadium redox flow } \\
\text { batteries }\end{array}$ & $\begin{array}{l}\text { coupling between the } \\
\text { components }\end{array}$ & [125] \\
\hline MnO-graphene & hydrothermal process & LIBs & nanosheets & [121] \\
\hline \multirow[t]{8}{*}{$\mathrm{Fe}_{3} \mathrm{O}_{4}$-graphene } & $\begin{array}{l}\text { combined hydrothermal } \\
\text { self-assembly, } \\
\text { freeze-drying and } \\
\text { thermal treatment }\end{array}$ & electrocatalyst (ORR) & 3D aerogel & [147] \\
\hline & $\begin{array}{l}\text { supercritical drying and } \\
\text { carbonizing hydrogel } \\
\text { precursors }\end{array}$ & enzyme immobilisation & aerogels & [148] \\
\hline & kirkendall process & LIBs & core-shell nanohollow & [161] \\
\hline & filtration process & $\begin{array}{l}\text { electrochemical } \\
\text { actuators }\end{array}$ & paper & [158] \\
\hline & $\begin{array}{l}\text { vacuum filtration and } \\
\text { thermal reduction } \\
\text { process }\end{array}$ & LIBs & flexible films & {$[146]$} \\
\hline & solvothermal treatment & LIBs & graphene-coated NPs & [162] \\
\hline & solution chemistry & regenerative adsorbent & NPs decorated on rGO & [167] \\
\hline & chemical synthesis & LIBs & $\begin{array}{l}\text { NP-anchored graphene } \\
\text { nanosheets }\end{array}$ & [163] \\
\hline \multirow[t]{3}{*}{$\mathrm{Fe}_{2} \mathrm{O}_{3}$-graphene } & \multirow[t]{2}{*}{ hydrothermal process } & $\begin{array}{l}\text { LIBs and arsenic } \\
\text { removal }\end{array}$ & network & {$[154]$} \\
\hline & & $\begin{array}{l}\text { nonenzymatic } \mathrm{H}_{2} \mathrm{O}_{2} \\
\text { biosensors }\end{array}$ & NPs decorated on rGO & [155] \\
\hline & $\begin{array}{l}\text { solvothermal induced } \\
\text { self-assembly }\end{array}$ & LIBs & aerogels & {$[166]$} \\
\hline \multirow[t]{5}{*}{$\mathrm{Co}_{3} \mathrm{O}_{4}$-graphene } & \multirow[t]{4}{*}{ chemical synthesis } & $\begin{array}{l}\text { catalyst (ORR and } \\
\text { ORE) }\end{array}$ & NPs on graphene & [170] \\
\hline & & LIBs & Nanowall arrays on rGO & [169] \\
\hline & & LIBs & $\begin{array}{l}\text { Graphene-anchored } \\
\text { NPs }\end{array}$ & [178] \\
\hline & & catalyst (ORR) & nanosheet & [176] \\
\hline & hydrothermal process & $\begin{array}{l}\text { oxidation of olefins and } \\
\text { alcohols }\end{array}$ & sandwich & {$[174]$} \\
\hline
\end{tabular}


Table 1: Important hybrid material synthesis procedures and their potential applications. (continued)

\begin{tabular}{|c|c|c|c|c|}
\hline \multirow[t]{3}{*}{ CoO-graphene } & chemical synthesis & ORR & $\begin{array}{l}\text { NPs assembled on } \\
\text { graphene }\end{array}$ & [189] \\
\hline & & LIBs & nanosheets & [187] \\
\hline & $\begin{array}{l}\text { assembly by } \\
\text { electrostatic forces }\end{array}$ & LIBs & $\begin{array}{l}\text { graphene-encapsulated } \\
\text { NPs }\end{array}$ & [185] \\
\hline \multirow[t]{4}{*}{$\mathrm{NiO}-$ graphene } & $\begin{array}{l}\text { electrophoretic } \\
\text { deposition and chemical } \\
\text { bath deposition }\end{array}$ & $\begin{array}{l}\text { electrochromic } \\
\text { performance }\end{array}$ & films & [196] \\
\hline & chemical process & $\mathrm{NO}_{2}$ sensors & 2D nanosheets & [204] \\
\hline & $\begin{array}{l}\text { chemical bath } \\
\text { deposition technique }\end{array}$ & supercapacitors & 3D foams & [203] \\
\hline & $\begin{array}{l}\text { microwave-assisted } \\
\text { synthesis }\end{array}$ & supercapacitors & graphene-wrapped NPs & [206] \\
\hline \multirow[t]{3}{*}{ CuO-graphene } & $\begin{array}{l}\text { spin-coating, Magnetron } \\
\text { sputtering }\end{array}$ & $\begin{array}{l}\text { blocking layer and } \mathrm{O}_{2} \\
\text { ion storage }\end{array}$ & multilayer & [217] \\
\hline & $\begin{array}{l}\text { vacuum filtration and } \\
\text { hydrothermal reduction }\end{array}$ & LIBs & lamellar paper & [336] \\
\hline & hydrothermal method & $\begin{array}{l}\text { electrochemical } \\
\text { capacitors }\end{array}$ & leaf-like NPs on GS & [223] \\
\hline \multirow[t]{2}{*}{$\mathrm{Cu}_{2} \mathrm{O}$-graphene } & hydrothermal process & $\mathrm{NO}_{2}$ sensor & mesocrystals & [214] \\
\hline & $\begin{array}{l}\text { chemical reduction } \\
\text { method }\end{array}$ & $\begin{array}{l}\text { electrochemical sensor } \\
\text { (glucose and } \mathrm{H}_{2} \mathrm{O}_{2} \text { ) }\end{array}$ & graphene-wrapped NPs & [211] \\
\hline \multirow[t]{7}{*}{ ZnO-graphene } & chemical synthesis & white LEDs & quasi-QDs & [224] \\
\hline & hydrothermal method & photocatalytic activity & nanomesh & [233] \\
\hline & $\begin{array}{l}\text { hydrothermal process } \\
\text { with surface } \\
\text { modification }\end{array}$ & wave absorption & $\begin{array}{l}\text { graphene-wrapped } \\
\text { hollow NPs }\end{array}$ & [228] \\
\hline & $\begin{array}{l}\text { functionalisation of NPs } \\
\text { followed by } \\
\text { hydrothermal method }\end{array}$ & photodetector & core-shell & [226] \\
\hline & $\begin{array}{l}\text { atomic layer deposition, } \\
\text { CVD }\end{array}$ & sensor (formaldehyde) & films & [266] \\
\hline & $\begin{array}{l}\text { thermal evaporation } \\
\text { technique }\end{array}$ & UV photodetector & $\begin{array}{l}\text { NWs on 3D graphene } \\
\text { foam }\end{array}$ & [275] \\
\hline & $\begin{array}{l}\text { freeze-drying, } \\
\text { subsequent heat } \\
\text { treatment method }\end{array}$ & LIBs & $\begin{array}{l}\text { NPs anchored on } \\
\text { graphene }\end{array}$ & [240] \\
\hline \multirow[t]{3}{*}{$\mathrm{NiCo}_{2} \mathrm{O}_{4}$-graphene } & $\begin{array}{l}\text { freeze-drying and } \\
\text { hydrothermal reduction }\end{array}$ & supercapacitors & 3D mesoporous & [307] \\
\hline & $\begin{array}{l}\text { polyol and thermal } \\
\text { annealing }\end{array}$ & electrocatalyst (ORR) & nanosheets & [299] \\
\hline & $\begin{array}{l}\text { hydrothermal method } \\
\text { followed by calcination }\end{array}$ & supercapacitors & $\begin{array}{l}\text { nanorods and } \\
\text { nanobundles }\end{array}$ & [306] \\
\hline $\mathrm{MnCo}_{2} \mathrm{O}_{4}$-graphene & chemical synthesis & catalyst (ORR) & NPs on GS & [29] \\
\hline \multirow[t]{3}{*}{$\mathrm{CoFe}_{2} \mathrm{O}_{4}$-graphene } & chemical synthesis & LIBs & films & [318] \\
\hline & solvothermal route & LIBs & sandwich & [317] \\
\hline & & catalyst (ORR) & NPs on GS & [309] \\
\hline \multirow[t]{2}{*}{$\mathrm{ZnFe}_{2} \mathrm{O}_{4}$-graphene } & hydrothermal synthesis & LIBs & octahedrons & [329] \\
\hline & deposition/precipitation & photocatalyst & multiporous microbricks & [332] \\
\hline \multirow[t]{2}{*}{$\mathrm{LiFePO}_{4}$-graphene } & $\begin{array}{l}\text { catalyst-assisted } \\
\text { self-assembly method }\end{array}$ & LIBs & $\begin{array}{l}\text { graphene-embedded } \\
\text { NPs }\end{array}$ & [288] \\
\hline & chemicals synthesis & LIBs & sandwich & [287] \\
\hline
\end{tabular}

large amount of graphene, preferably with surface modification. By tuning the surface chemistry of graphene, the fluorescent properties can be changed accordingly which enables its poten- tial application in photovoltaics, sensors and also in bioimaging. The number of publications related to graphene and graphene-based materials has increased exponentially in recent 
years. However, there is still need for the scientific community to develop graphene-based models, hybrid materials and devices, and their possible applications in various fields. By improving the quality of the synthesised graphene, better quality hybrids can be prepared for different applications.

\section{Perspectives}

Knowledge of GO chemistry will provide valuable input about its reactive properties and the properties of the graphene derived from it. Controlled methods of graphene synthesis are particularly important for the controlled growth of layers, which still remains to be established. Regarding the fabrication of graphene NP hybrids, the key obstacle lies in the reproducibility of the structure. For the synthesis of graphene-encapsulated NPs, the difficulty is that the thin graphene layer is not ideally formed as a uniform layer on all the NPs. Thus, the design and synthesis of new graphene-based nanostructures and architectures with uniform structure will be an important task for the future. It is important to mention that no such unique analysis technique has been introduced which can confirm that all the NPs are uniformly coated. In most reports directed at graphene-encapsulated structures, a quasi-core-shell structure was obtained instead of the desired core-shell structure.

By achieving a high level of uniformity and reproducibility of graphene-NP hybrids, the electrical properties of the devices can be optimised which will lead to higher sensitivity and selectivity. Inexpensive and large-scale fabrication of defect-free graphene is still a challenge due to the existence of defects or oxidation sites in graphene, which is partially restored in graphene derived from GO. However, there is no doubt that more efficient synthetic strategies for graphene and graphenebased hybrids will be developed in an economically feasible quantity, leading to the commercialisation of graphene in the near future. Some research shows that the surfactants and the reductants used for the synthesis of the hybrid materials have a detrimental effect. In this sense, the biocompatibility and toxicity of the chemicals should be investigated to enable application of the hybrid materials in biomedical applications. Most of the applications of TMO-graphene hybrid materials are in LIBs, although further study is required to gain control over the phase and morphology of the NPs for this application. A prerequisite is a well-mastered growth synthesis to obtain a well-defined uniform structure of graphene. Control over the interface and interaction between NPs and graphene is necessary to enhance the performance of LIBs. Much attention is devoted to the application of graphene-NP hybrids in supercapacitor applications but more research is necessary. During the charge-discharge process, the graphene layers become aggregated, which degrades the electrode material. In some cases, the electrode materials are contaminated by impurities introduced from the incomplete reduction of GO. When using graphene-TMO hybrids as a photocatalyst, the improved performance in the catalytic properties is generally ascribed to the extended absorption and faster charge transfer in graphene as compared to TMOs. Therefore, research on the interfacial status of the hybrid is important to obtain a detailed understanding of the origin of the improvement.

Further challenges exist in the application of graphene-TMO NP hybrids on the industrial scale. Some advanced applications of the graphene-based hybrids require particular understanding of the contact between the surface of the graphene and the NPs, which will have a direct impact on the properties of the hybrid. Despite the enormous efforts and huge attention, a significant breakthrough application of graphene and graphene-based materials in energy harvesting systems has not been achieved to date, but solutions to the key challenges appear within reach. In view of the manifold of potential applications, each having different requirements regarding material properties, it can be anticipated that the research on graphene-TMO NP hybrid materials will have a very bright future.

\section{References}

1. Novoselov, K. S.; Geim, A. K.; Morozov, S. V.; Jiang, D.; Zhang, Y.; Dubonos, S. V.; Grigorieva, I. V.; Firsov, A. A. Science 2004, 306, 666-669. doi:10.1126/science.1102896

2. Geim, A. K.; Novoselov, K. S. Nat. Mater. 2007, 6, 183-191. doi:10.1038/nmat1849

3. Geim, A. K. Science 2009, 324, 1530-1534. doi:10.1126/science.1158877

4. Suk, J. W.; Piner, R. D.; An, J.; Ruoff, R. S. ACS Nano 2010, 4, 6557-6564. doi:10.1021/nn101781v

5. Lee, C.; Wei, X.; Kysar, J. W.; Hone, J. Science 2008, 321, 385-388. doi:10.1126/science.1157996

6. Balandin, A. A.; Ghosh, S.; Bao, W. Z.; Calizo, I.; Teweldebrhan, D.; Miao, F.; Lau, C. N. Nano Lett. 2008, 8, 902-907. doi:10.1021/nl0731872

7. Du, X.; Skachko, I.; Barker, A.; Andrei, E. Y. Nat. Nanotechnol. 2008, 3, 491-495. doi:10.1038/nnano.2008.199

8. Zhu, Y.; Murali, S.; Cai, W.; Li, X.; Suk, J. W.; Potts, J. R.; Ruoff, R. S. Adv. Mater. 2010, 22, 3906-3924. doi:10.1002/adma.201001068

9. Pang, S.; Hernandez, Y.; Feng, X.; Müllen, K. Adv. Mater. 2011, 23, 2779-2795. doi:10.1002/adma.201100304

10. Nair, R. R.; Blake, P.; Grigorenko, A. N.; Novoselov, K. S.; Booth, T. J.; Stauber, T.; Peres, N. M. R.; Geim, A. K. Science 2008, 320, 1308. doi:10.1126/science.1156965

11. Pham, C. V.; Krueger, M.; Eck, M.; Weber, S.; Erdem, E. Appl. Phys. Lett. 2014, 104, 132102. doi:10.1063/1.4870297

12. Liu, C.; Yu, Z.; Neff, D.; Zhamu, A.; Jang, B. Z. Nano Lett. 2010, 10, 4863-4868. doi:10.1021/nl102661q

13. He, Q. Y.; Wu, S. X.; Yin, Z. Y.; Zhang, H. Chem. Sci. 2012, 3, 1764-1772. doi:10.1039/c2sc20205k

14. Wang, Z. L. J. Phys.: Condens. Matter 2004, 16, R829-R858. doi:10.1088/0953-8984/16/25/R01 
15. Jing, L.; Qu, Y.; Wang, B.; Li, S.; Jiang, B.; Yang, L.; Fu, W.; Fu, H.; Sun, J. Sol. Energy Mater. Sol. Cells 2006, 90, 1773-1787. doi:10.1016/j.solmat.2005.11.007

16. Ni, M.; Leung, M. K. H.; Leung, D. Y. C.; Sumathy, K. Renewable Sustainable Energy Rev. 2007, 11, 401-425. doi:10.1016/j.rser.2005.01.009

17. Chen, X.; Mao, S. S. Chem. Rev. 2007, 107, 2891-2959. doi:10.1021/cr0500535

18. Brock, S. L.; Duan, N.; Tian, Z. R.; Giraldo, O.; Zhou, H.; Suib, S. L. Chem. Mater. 1998, 10, 2619-2628. doi:10.1021/cm980227h

19. Laurent, S.; Forge, D.; Port, M.; Roch, A.; Robic, C.; Elst, L. V.; Muller, R. N. Chem. Rev. 2008, 108, 2064-2110. doi:10.1021/cr068445e

20. Viswanatha, R.; Amenitsch, H.; Sarma, D. D. J. Am. Chem. Soc. 2007, 129, 4470-4475. doi:10.1021/ja068161b

21. Khan, M.; Tahir, M. N.; Adil, S. F.; Khan, H. U.; Siddiqui, M. R. H.; Al-warthan, A. A.; Tremel, W. J. Mater. Chem. A 2015, 3, 18753-18808. doi:10.1039/C5TA02240A

22. Yin, P. T.; Kim, T.-H.; Choi, J.-W.; Lee, K.-B. Phys. Chem. Chem. Phys. 2013, 15, 12785-12799. doi:10.1039/c3cp51901e

23. Xiang, Q. J.; Yu, J. G.; Jaroniec, M. Chem. Soc. Rev. 2012, 41, 782-796. doi:10.1039/C1CS15172J

24. Atif, R.; Inam, F. Beilstein J. Nanotechnol. 2016, 7, 1174-1196. doi:10.3762/bjnano.7.109

25. Paek, S.-M.; Yoo, E.; Honma, I. Nano Lett. 2009, 9, 72-75. doi:10.1021/nl802484w

26. Poizot, P.; Laruelle, S.; Grugeon, S.; Dupont, L.; Tarascon, J.-M. Nature 2000, 407, 496-499. doi:10.1038/35035045

27. Yu, A.; Park, H. W.; Davies, A.; Higgins, D. C.; Chen, Z.; Xiao, X. J. Phys. Chem. Lett. 2011, 2, 1855-1860. doi:10.1021/jz200836h

28. Zhang, L. L.; Zhao, X.; Stoller, M. D.; Zhu, Y.; Ji, H.; Murali, S.; Wu, Y.; Perales, S.; Clevenger, B.; Ruoff, R. S. Nano Lett. 2012, 12, 1806-1812. doi:10.1021/nl203903z

29. Liang, Y.; Wang, H.; Zhou, J.; Li, Y.; Wang, J.; Regier, T.; Dai, H. J. Am. Chem. Soc. 2012, 134, 3517-3523. doi:10.1021/ja210924t

30. Varghese, J.; Varghese, K. T. Mater. Chem. Phys. 2015, 167, 258-264. doi:10.1016/j.matchemphys.2015.10.041

31. Hernandez, Y.; Nicolosi, V.; Lotya, M.; Blighe, F. M.; Sun, Z.; De, S.; McGovern, I. T.; Holland, B.; Byrne, M.; Gun'ko, Y. K.; Boland, J. J.; Niraj, P.; Duesberg, G.; Krishnamurthy, S.; Goodhue, R.; Hutchison, J.; Scardaci, V.; Ferrari, A. C.; Coleman, J. N Nat. Nanotechnol. 2008, 3, 563-568. doi:10.1038/nnano.2008.215

32. Zhang, H.-B.; Wang, J.-W.; Yan, Q.; Zheng, W.-G.; Chen, C.; Yu, Z.-Z. J. Mater. Chem. 2011, 21, 5392-5397. doi:10.1039/c1jm10099h

33. Quintana, M.; Tapia, J. I.; Prato, M. Beilstein J. Nanotechnol. 2014, 5, 2328-2338. doi:10.3762/bjnano.5.242

34. Yang, W.; Chen, G.; Shi, Z.; Liu, C.-C.; Zhang, L.; Xie, G.; Cheng, M.; Wang, D.; Yang, R.; Shi, D.; Watanabe, K.; Taniguchi, T.; Yao, Y.; Zhang, Y.; Zhang, G. Nat. Mater. 2013, 12, 792-797. doi:10.1038/nmat3695

35. Wei, D.; Liu, Y.; Wang, Y.; Zhang, H.; Huang, L.; Yu, G. Nano Lett. 2009, 9, 1752-1758. doi:10.1021/nl803279t

36. Reina, A.; Jia, X.; Ho, J.; Nezich, D.; Son, H.; Bulovic, V.; Dresselhaus, M. S.; Kong, J. Nano Lett. 2009, 9, 30-35. doi:10.1021/nl801827v
37. Schniepp, H. C.; Li, J.-L.; McAllister, M. J.; Sai, H.; Herrera-Alonso, M.; Adamson, D. H.; Prud'homme, R. K.; Car, R.; Saville, D. A.; Aksay, I. A. J. Phys. Chem. B 2006, 110, 8535-8539. doi:10.1021/jp060936f

38. Park, S.; Ruoff, R. S. Nat. Nanotechnol. 2009, 4, 217-224. doi:10.1038/nnano.2009.58

39. Li, X.; Cai, W.; An, J.; Kim, S.; Nah, J.; Yang, D.; Piner, R.; Velamakanni, A.; Jung, I.; Tutuc, E.; Banerjee, S. K.; Colombo, L.; Ruoff, R. S. Science 2009, 324, 1312-1314. doi:10.1126/science. 1171245

40. Capasso, A.; Dikonimos, T.; Sarto, F.; Tamburrano, A.; De Bellis, G.; Sarto, M. S.; Faggio, G.; Malara, A.; Messina, G.; Lisi, N. Beilstein J. Nanotechnol. 2015, 6, 2028-2038. doi:10.3762/bjnano.6.206

41. Subrahmanyam, K. S.; Panchakarla, L. S.; Govindaraj, A.; Rao, C. N. R. J. Phys. Chem. C 2009, 113, 4257-4259. doi:10.1021/jp900791y

42. Sutter, P. W.; Flege, J.-I.; Sutter, E. A. Nat. Mater. 2008, 7, 406-411. doi:10.1038/nmat2166

43. Schafhaeutl, C. Philos. Mag. 1840, 16, 570-590. doi:10.1080/14786444008650094

44. Hummers, W. S., Jr.; Offeman, R. E. J. Am. Chem. Soc. 1958, 80 , 1339. doi:10.1021/ja01539a017

45. Pei, S.; Cheng, H.-M. Carbon 2012, 50, 3210-3228. doi:10.1016/j.carbon.2011.11.010

46. McAllister, M. J.; Li, J.-L.; Adamson, D. H.; Schniepp, H. C.; Abdala, A. A.; Liu, J.; Herrera-Alonso, M.; Milius, D. L.; Car, R.; Prud'homme, R. K.; Aksay, I. A. Chem. Mater. 2007, 19, 4396-4404. doi:10.1021/cm0630800

47. Sun, X.; Luo, D.; Liu, J.; Evans, D. G. ACS Nano 2010, 4, 3381-3389. doi:10.1021/nn1000386

48. An, C.; Wang, Y.; Wang, Y.; Liu, G.; Li, L.; Qiu, F.; Xu, Y.; Jiao, L.; Yuan, H. RSC Adv. 2013, 3, 4628-4633. doi:10.1039/c3ra00079f

49. Xu, Y.; Sheng, K.; Li, C.; Shi, G. J. Mater. Chem. 2011, 21 , 7376-7380. doi:10.1039/c1jm10768b

50. Bera, R.; Kundu, S.; Patra, A. ACS Appl. Mater. Interfaces 2015, 7, 13251-13259. doi:10.1021/acsami.5b03800

51. Stankovich, S.; Dikin, D. A.; Piner, R. D.; Kohlhaas, K. A.; Kleinhammes, A.; Jia, Y.; Wu, Y.; Nguyen, S. T.; Ruoff, R. S. Carbon 2007, 45, 1558-1565. doi:10.1016/j.carbon.2007.02.034

52. Stankovich, S.; Piner, R. D.; Chen, X.; Wu, N.; Nguyen, S. T.; Ruoff, R. S. J. Mater. Chem. 2006, 16, 155-158. doi:10.1039/B512799H

53. Stankovich, S.; Dikin, D. A.; Dommett, G. H. B.; Kohlhaas, K. M.; Zimney, E. J.; Stach, E. A.; Piner, R. D.; Nguyen, S. T.; Ruoff, R. S. Nature 2006, 442, 282-286. doi:10.1038/nature04969

54. Shin, H.-J.; Kim, K. K.; Benayad, A.; Yoon, S.-M.; Park, H. K.; Jung, I.-S.; Jin, M. H.; Jeong, H.-K.; Kim, J. M.; Choi, J.-Y.; Lee, Y. H. Adv. Funct. Mater. 2009, 19, 1987-1992. doi:10.1002/adfm.200900167

55. Periasamy, M.; Thirumalaikumar, P. J. Organomet. Chem. 2000, 609, 137-151. doi:10.1016/S0022-328X(00)00210-2

56. Wang, G.; Yang, J.; Park, J.; Gou, X.; Wang, B.; Liu, H.; Yao, J. J. Phys. Chem. C 2008, 112, 8192-8195. doi:10.1021/jp710931h

57. Wu, Z.-S.; Ren, W.; Gao, L.; Liu, B.; Jiang, C.; Cheng, H.-M. Carbon 2009, 47, 493-499. doi:10.1016/j.carbon.2008.10.031

58. Fan, X.; Peng, W.; Li, Y.; Li, X.; Wang, S.; Zhang, G.; Zhang, F. Adv. Mater. 2008, 20, 4490-4493. doi:10.1002/adma.200801306 
59. Boehm, H. P.; Clauss, A.; Fischer, G. O.; Hofmann, U. Z. Anorg. Allg. Chem. 1962, 316, 119-127. doi:10.1002/zaac.19623160303

60. Fernández-Merino, M. J.; Guardia, L.; Paredes, J. I.; Villar-Rodil, S.; Solis-Fernández, P.; Martínez-Alonso, A.; Tascón, J. M. D. J. Phys. Chem. C 2010, 114, 6426-6432. doi:10.1021/jp100603h

61. Han, H. J.; Chen, Y. N.; Wang, Z. J. RSC Adv. 2015, 5, 92940-92946. doi:10.1039/C5RA19268D

62. Zhu, Y.; Murali, S.; Stoller, M. D.; Velamakanni, A.; Piner, R. D.; Ruoff, R. S. Carbon 2010, 48, 2118-2122. doi:10.1016/j.carbon.2010.02.001

63. Zhou, M.; Wang, Y.; Zhai, Y.; Zhai, J.; Ren, W.; Wang, F.; Dong, S. Chem. - Eur. J. 2009, 15, 6116-6120. doi:10.1002/chem.200900596

64. Ramesha, G. K.; Sampath, S. J. Phys. Chem. C 2009, 113, 7985-7989. doi:10.1021/jp811377n

65. Kudin, K. N.; Ozbas, B.; Schniepp, H. C.; Prud'homme, R. K.; Aksay, I. A.; Car, R. Nano Lett. 2008, 8, 36-41. doi:10.1021/nl071822y

66. Williams, G.; Seger, B.; Kamat, P. V. ACS Nano 2008, 2, 1487-1491. doi:10.1021/nn800251f

67. Wang, H.; Robinson, J. T.; Li, X.; Dai, H. J. Am. Chem. Soc. 2009, 131, 9910-9911. doi:10.1021/ja904251p

68. Yuan, B.; Bao, C.; Qian, X.; Wen, P.; Xing, W.; Song, L.; Hu, Y. Mater. Res. Bull. 2014, 55, 48-52. doi:10.1016/j.materresbull.2014.04.016

69. Gao, X.; Jang, J.; Nagase, S. J. Phys. Chem. C 2010, 114, 832-842. doi:10.1021/jp909284g

70. Pei, S.; Zhao, J.; Du, J.; Ren, W.; Cheng, H.-M. Carbon 2010, 48, 4466-4474. doi:10.1016/j.carbon.2010.08.006

71. Wei, Z.; Chen, Y.; Wang, J.; Su, D.; Tang, M.; Mao, S.; Wang, Y. ACS Catal. 2016, 6, 5816-5822. doi:10.1021/acscatal.6b01240

72. Lee, J. S.; You, K. H.; Park, C. B. Adv. Mater. 2012, 24, 1084-1088. doi:10.1002/adma.201104110

73. Zhang, Y. L.; Li, D. Y.; Zhang, Y. G.; Zhou, X. F.; Guoabc, S. J.; Yang, L. B. J. Mater. Chem. A 2014, 2, 8273-8280. doi:10.1039/c4ta00088a

74. Qin, J.; Cao, M.; Li, N.; Hu, C. J. Mater. Chem. 2011, 21, 17167-17174. doi:10.1039/c1jm12692j

75. Myung, S.; Solanki, A.; Kim, C.; Park, J.; Kim, K. S.; Lee, K.-B. Adv. Mater. 2011, 23, 2221-2225. doi:10.1002/adma.201100014

76. Wu, Z.-S.; Wang, D.-W.; Ren, W.; Zhao, J.; Zhou, G.; Li, F.; Cheng, H.-M. Adv. Funct. Mater. 2010, 20, 3595-3602. doi:10.1002/adfm.201001054

77. Lv, W.; Sun, F.; Tang, D.-M.; Fang, H.-T.; Liu, C.; Yang, Q.-H.; Cheng, H.-M. J. Mater. Chem. 2011, 21, 9014-9019. doi:10.1039/c1jm10400d

78. Pottier, A.; Chanéac, C.; Tronc, E.; Mazerolles, L.; Jolivet, J.-P. J. Mater. Chem. 2001, 11, 1116-1121. doi:10.1039/b100435m

79. Lee, S.; Cho, I.-S.; Lee, J. H.; Kim, D. H.; Kim, D. W.; Kim, J. Y.; Shin, H.; Lee, J.-K.; Jung, H. S.; Park, N.-G.; Kim, K.; Ko, M. J.; Hong, K. S. Chem. Mater. 2010, 22, 1958-1965. doi:10.1021/cm902842k

80. Liu, L.; Liu, H.; Zhao, Y.-P.; Wang, Y.; Duan, Y.; Gao, G.; Ge, M.; Chen, W. Environ. Sci. Technol. 2008, 42, 2342-2348. doi:10.1021/es070980o

81. Ng, Y. H.; Lightcap, I. V.; Goodwin, K.; Matsumura, M.; Kamat, P. V. J. Phys. Chem. Lett. 2010, 1, 2222-2227. doi:10.1021/jz100728z

82. Kamat, P. V. J. Phys. Chem. Lett. 2011, 2, 242-251. doi:10.1021/jz101639v
83. Štengl, V.; Popelková, D.; Vláčil, P. J. Phys. Chem. C 2011, 115, 25209-25218. doi:10.1021/jp207515z

84. Lambert, T. N.; Chavez, C. A.; Hernandez-Sanchez, B.; Lu, P.; Bell, N. S.; Ambrosini, A.; Friedman, T.; Boyle, T. J.; Wheeler, D. R.; Huber, D. L. J. Phys. Chem. C 2009, 113, 19812-19823. doi:10.1021/jp905456f

85. Xin, X.; Zhou, X.; Wu, J.; Yao, X.; Liu, Z. ACS Nano 2012, 6, 11035-11043. doi:10.1021/nn304725m

86. Ramadoss, A.; Kim, S. J. Carbon 2013, 63, 434-445. doi:10.1016/j.carbon.2013.07.006

87. Cheng, G.; Akhtar, M. S.; Yang, O-B.; Stadler, F. J. ACS Appl. Mater. Interfaces 2013, 5, 6635-6642. doi:10.1021/am4013374

88. Liang, Y.; Wang, H.; Casalongue, H. S.; Chen, Z.; Dai, H. J. Nano Res. 2010, 3, 701-705. doi:10.1007/s12274-010-0033-5

89. Zhang, Z.; Xiao, F.; Guo, Y.; Wang, S.; Liu, Y. ACS Appl. Mater. Interfaces 2013, 5, 2227-2233. doi:10.1021/am303299r

90. Tu, W.; Zhou, Y.; Liu, Q.; Yan, S.; Bao, S.; Wang, X.; Xiao, M.; Zou, Z. Adv. Funct. Mater. 2013, 23, 1743-1749. doi:10.1002/adfm.201202349

91. Liu, H.; Cao, K.; Xu, X.; Jiao, L.; Wang, Y.; Yuan, H. ACS Appl. Mater. Interfaces 2015, 7, 11239-11245. doi:10.1021/acsami.5b02724

92. Wang, D.; Choi, D.; Li, J.; Yang, Z.; Nie, Z.; Kou, R.; Hu, D.; Wang, C.; Saraf, L. V.; Zhang, J.; Aksay, I. A.; Liu, J. ACS Nano 2009, 3, 907-914. doi:10.1021/nn900150y

93. Manga, K. K.; Zhou, Y.; Yan, Y.; Loh, K. P. Adv. Funct. Mater. 2009, 19, 3638-3643. doi:10.1002/adfm.200900891

94. Xia, B. Y.; Wang, B.; Wu, H. B.; Liu, Z.; Wang, X.; Lou, X. W. J. Mater. Chem. 2012, 22, 16499-16505. doi:10.1039/c2jm32816j

95. Tang, Y.-B.; Lee, C.-S.; Xu, J.; Liu, Z.-T.; Chen, Z.-H.; He, Z.; Cao, Y.-L.; Yuan, G.; Song, H.; Chen, L.; Luo, L.; Cheng, H.-M.; Zhang, W.-J.; Bello, I.; Lee, S.-T. ACS Nano 2010, 4, 3482-3488. doi:10.1021/nn100449w

96. Hu, T.; Sun, X.; Sun, H.; Yu, M.; Lu, F.; Liu, C.; Lian, J. Carbon 2003, 51, 322-326. doi:10.1016/j.carbon.2012.08.059

97. Zhang, J.; Zhu, Z.; Tang, Y.; Feng, X. J. Mater. Chem. A 2013, 1, 3752-3756. doi:10.1039/c3ta01386c

98. Qiu, Y.; Yan, K.; Yang, S.; Jin, L.; Deng, H.; Li, W. ACS Nano 2010, 4, 6515-6526. doi:10.1021/nn101603g

99. Li, N.; Liu, G.; Zhen, C.; Li, F.; Zhang, L.; Cheng, H.-M. Adv. Funct. Mater. 2011, 21, 1717-1722. doi:10.1002/adfm.201002295

100.Sordello, F.; Odorici, E.; Hu, K.; Minero, C.; Cerruti, M.; Calza, P. Nanoscale 2016, 8, 3407-3415. doi:10.1039/C5NR07257C

101.Zhao, C.-e; Wang, W.-J.; Sun, D.; Wang, X.; Zhang, J.-R.; Zhu, J.-J. Chem. - Eur. J. 2014, 20, 7091-7097. doi:10.1002/chem.201400272

102.Anandan, S.; Rao, T. N.; Sathish, M.; Rangappa, D.; Honma, I.; Miyauchi, M. ACS Appl. Mater. Interfaces 2013, 5, 207-212. doi:10.1021/am302557z

103. Yamauchi, T.; Isobe, M.; Ueda, Y. Solid State Sci. 2005, 7, 874-881. doi:10.1016/j.solidstatesciences.2005.01.024

104.Manning, T. D.; Parkin, I. P.; Blackman, C.; Qureshi, U. J. Mater. Chem. 2005, 15, 4560-4566. doi:10.1039/b510552h

105. Piccirillo, C.; Binions, R.; Parkin, I. P. Chem. Vap. Deposition 2007, 13, 145-151. doi:10.1002/cvde.200606540

106. Avansi, W., Jr.; Ribeiro, C.; Leite, E. R.; Mastelaro, V. R. Cryst. Growth Des. 2009, 9, 3626-3631. doi:10.1021/cg900373f 
107.Cao, A.-M.; Hu, J.-S.; Liang, H.-P.; Wan, L.-J. Angew. Chem., Int. Ed. 2005, 44, 4391-4395. doi:10.1002/anie.200500946

108.Deng, L.; Zhang, G.; Kang, L.; Lei, Z.; Liu, C.; Liu, Z.-H. Electrochim. Acta 2013, 112, 448-457. doi:10.1016/j.electacta.2013.08.158

109.Kim, H.; Kim, Y.; Kim, T.; Jang, A-R.; Jeong, H. Y.; Han, S. H.; Yoon, D. H.; Shin, H. S.; Bae, D. J.; Kim, K. S.; Yang, W. S. Nanoscale 2013, 5, 2632-2636. doi:10.1039/c3nr34054f

110.Chao, D.; Zhu, C.; Xia, X.; Liu, J.; Zhang, X.; Wang, J.; Liang, P.; Lin, J.; Zhang, H.; Shen, Z.-X.; Fan, H.-J. Nano Lett. 2015, 15, 565-573. doi:10.1021/nl504038s

111.Yang, S.; Gong, Y.; Liu, Z.; Zhan, L.; Hashim, D. P.; Ma, L.; Vajtai, R.; Ajayan, P. M. Nano Lett. 2013, 13, 1596-1601. doi:10.1021/nl400001u

112.Nethravathi, C.; Viswanath, B.; Michael, J.; Rajamath, M. Carbon 2012, 50, 4839-4846. doi:10.1016/j.carbon.2012.06.010

113.Nethravathi, C.; Rajamathi, C. R.; Rajamathi, M.; Gautam, U. K.; Wang, X.; Golberg, D.; Bando, Y. ACS Appl. Mater. Interfaces 2013, 5, 2708-2714. doi:10.1021/am400202v

114.Liu, Q.; Li, Z.-F.; Liu, Y.; Zhang, H.; Ren, Y.; Sun, C.-J.; Lu, W.; Zhou, Y.; Stanciu, L.; Stach, E. A.; Xie, J. Nat. Commun. 2014, 6, 6127. doi:10.1038/ncomms 7127

115.Han, C.; Yan, M.; Mai, L.; Tian, X.; Xu, L.; Xu, X.; An, Q.; Zhao, Y.; Ma, X.; Xie, J. Nano Energy 2013, 2, 916-922. doi:10.1016/j.nanoen.2013.03.012

116.Rui, X.; Zhu, J.; Sim, D.; Xu, C.; Zeng, Y.; Hng, H.; Lim, T. M.; Yan, Q. Y. Nanoscale 2011, 3, 4752-4758. doi:10.1039/c1nr10879d

117.Kim, H.; Kim, Y.; Kim, K. S.; Jeong, H. Y.; Jang, A-R.; Han, S. H.; Yoon, D. H.; Suh, K. S.; Shin, H. S.; Kim, T.; Yang, W. S. ACS Nano 2013, 7, 5769-5776. doi:10.1021/nn400358x

118.Wen, C.; Gao, X.; Huang, T.; Wu, X.; Xu, L.; Yu, J.; Zhang, H.; Zhang, Z.; Han, J.; Ren, H. Int. J. Hydrogen Energy 2016, 41, 11099-11107. doi:10.1016/j.jijydene.2016.05.051

119.Song, C.; Gui, Y.; Xing, X.; Zhang, W. Mater. Chem. Phys. 2016, 173 , 460-466. doi:10.1016/j.matchemphys.2016.02.039

120.Chen, C.; Jian, H.; Fu, X.; Ren, Z.; Yan, M.; Qian, G.; Wang, Z. RSC Adv. 2014, 4, 5367-5370. doi:10.1039/c3ra45976d

121.Zhang, K.; Han, P.; Gu, L.; Zhang, L.; Liu, Z.; Kong, Q.; Zhang, C.; Dong, S.; Zhang, Z.; Yao, J.; Xu, H.; Cui, G.; Chen, L. ACS Appl. Mater. Interfaces 2012, 4, 658-664. doi:10.1021/am201173z

122.Su, L.; Wu, X.; Hei, J.; Wang, L.; Wang, Y. Part. Part. Syst. Charact. 2015, 32, 721-727. doi:10.1002/ppsc.201500002

123.Luo, Y.; Fan, S.; Hao, N.; Zhong, S.; Liu, W. Dalton Trans. 2014, 43, 15317-15320. doi:10.1039/C4DT01695E

124.Park, S.-K.; Jin, A.; Yu, S.-H.; Ha, J.; Jang, B.; Bong, S.; Woo, S.; Sung, Y.-E.; Piao, Y. Electrochim. Acta 2014, 120, 452-459. doi:10.1016/j.electacta.2013.12.018

125. Ejigu, A.; Edwards, M.; Walsh, D. A. ACS Catal. 2015, 5, 7122-7130. doi:10.1021/acscatal.5b01973

126.Li, L.; Seng, K. H.; Liu, H.; Nevirkovets, I. P.; Guo, Z. Electrochim. Acta 2013, 87, 801-808. doi:10.1016/j.electacta.2012.08.127

127.Qu, J.; Shi, L.; He, C.; Gao, F.; Li, B.; Zhou, Q.; Hu, H.; Shao, G.; Wang, X.; Quu, J. Carbon 2014, 66, 485-492. doi:10.1016/j.carbon.2013.09.025

128.Yao, Y.; Xu, C.; Yu, S.; Zhang, D.; Wang, S. Ind. Eng. Chem. Res. 2013, 52, 3637-3645. doi:10.1021/ie303220x
129.Ding, Z.; Qing, L.; QianYi, C.; YanChao, Z.; Yi, C.; Tao, W.; BaoHang, H. Chin. Sci. Bull. 2012, 57, 3059-3064. doi:10.1007/s11434-012-5158-3

130.Duan, J.; Chen, S.; Dai, S.; Qiao, S. Z. Adv. Funct. Mater. 2014, 24, 2072-2078. doi:10.1002/adfm.201302940

131.Li, L.; Hu, Z.; Yang, Y.; Liang, P.; Lu, A.; Xu, H.; Hu, Y.; Wu, H. Chin. J. Chem. 2013, 31, 1290-1298. doi:10.1002/cjoc.201300324

132. Hu, Y.; Guan, C.; Feng, G.; Ke, Q.; Huang, X.; Wang, J. Adv. Funct. Mater. 2015, 25, 7291-7299. doi:10.1002/adfm.201503528

133.Yang, X.; He, Y.; Bai, Y.; Zhang, J.; Kang, L.; Xu, H.; Shi, F.; Lei, Z.; Liu, Z.-H. Electrochim. Acta 2016, 188, 398-405. doi:10.1016/j.electacta.2015.12.024

134.Xu, H.; Qu, Z.; Zong, C.; Huang, W.; Quan, F.; Yan, N. Environ. Sci. Technol. 2015, 49, 6823-6830. doi:10.1021/es505978n

135.Bag, S.; Roy, K.; Gopinath, C. S.; Raj, C. R. ACS Appl. Mater. Interfaces 2014, 6, 2692-2699. doi:10.1021/am405213z

136.Wang, H.; Cui, L.-F.; Yang, Y.; Casalongue, H. S.; Robinson, J. T.; Liang, Y.; Cui, Y.; Dai, H. J. Am. Chem. Soc. 2010, 132, 13978-13980. doi:10.1021/ja105296a

137. Mai, Y. J.; Zhang, D.; Qiao, Y. Q.; Gu, C. D.; Wang, X. L.; Tu, J. P. J. Power Sources 2012, 216, 201-207. doi:10.1016/j.jpowsour.2012.05.084

138.Lee, J. W.; Hall, A. S.; Kim, J.-D.; Mallouk, T. E. Chem. Mater. 2012, 24, 1158-1164. doi:10.1021/cm203697w

139.Dong, X.; Wang, X.; Wang, L.; Song, H.; Li, X.; Wang, L.; Chan-Park, M. B.; Li, C. M.; Chen, P. Carbon 2012, 50, 4865-4870. doi:10.1016/j.carbon.2012.06.014

140.Peng, L.; Peng, X.; Liu, B.; Wu, C.; Xie, Y.; Yu, G. Nano Lett. 2013, 13, 2151-2157. doi:10.1021/nl400600x

141.Zhu, J.; He, J. ACS Appl. Mater. Interfaces 2012, 4, 1770-1776. doi:10.1021/am3000165

142.Sun, Y.; Hu, X.; Luo, W.; Xia, F.; Huang, Y. Adv. Funct. Mater. 2013, 23, 2436-2444. doi:10.1002/adfm.201202623

143. Chen, J.; Xu, L.; Li, W.; Gou, X. Adv. Mater. 2005, 17, 582-586. doi:10.1002/adma.200401101

144.Wang, T.; Liu, Z.; Lu, M.; Wen, B.; Ouyang, Q.; Chen, Y.; Zhu, C.; Gao, P.; Li, C.; Cao, M.; Qi, L. J. Appl. Phys. 2013, 113, 024314. doi:10.1063/1.4774243

145.Tian, L.; Zhuang, Q.; Li, J.; Wu, C.; Shi, Y.; Sun, S. Electrochim. Acta 2012, 65, 153-158. doi:10.1016/j.electacta.2012.01.034

146.Wang, R.; Xu, C.; Sun, J.; Gao, L.; Lin, C. J. Mater. Chem. A 2013, 1, 1794-1800. doi:10.1039/C2TA00753C

147.Wu, Z.-S.; Yang, S.; Sun, Y.; Parvez, K.; Feng, X.; Müllen, K. J. Am. Chem. Soc. 2012, 134, 9082-9085. doi:10.1021/ja3030565

148. Chen, L.; Wei, B.; Zhang, X.; Li, C. Small 2013, 9, 2331-2340. doi:10.1002/smll.201202923

149. Ma, Z.; Huang, X.; Dou, S.; Wu, J.; Wang, S. J. Phys. Chem. C 2014, 118, 17231-17239. doi:10.1021/jp502226j

150.Zhang, M.; Qu, B.; Lei, D.; Chen, Y.; Yu, X.; Chen, L.; Li, Q.; Wang, Y.; Wang, T. J. Mater. Chem. 2012, 22, 3868-3874. doi:10.1039/c2jm15927a

151.Xue, X.-Y.; Ma, C.-H.; Cui, C.-X.; Xing, L.-L. Solid State Sci. 2011, 13, 1526-1530. doi:10.1016/j.solidstatesciences.2011.05.015

152.Zhu, X.; Zhu, Y.; Murali, S.; Stollers, M. D.; Ruoff, R. S. ACS Nano 2011, 5, 3333-3338. doi:10.1021/nn200493r

153.Xiao, L.; Wu, D.; Han, S.; Huang, Y.; Li, S.; He, M.; Zhang, F.; Feng, X. ACS Appl. Mater. Interfaces 2013, 5, 3764-3769. doi:10.1021/am400387t 
154.Li, L.; Zhou, G.; Weng, Z.; Shan, X.-Y.; Li, F.; Cheng, H.-M. Carbon 2014, 67, 500-507. doi:10.1016/j.carbon.2013.10.022

155.Wang, M.-Y.; Shen, T.; Wang, M.; Zhang, D.-E.; Tong, Z.-w.; Chen, J. Sens. Actuators, B 2014, 190, 645-650. doi:10.1016/j.snb.2013.08.091

156.Xue, W.-d.; Zhao, R.; Du, X.; Xu, F.-w.; Xu, M.; Wei, K.-x. Mater. Res. Bull. 2014, 50, 285-291. doi:10.1016/j.materresbull.2013.11.027

157.Yang, S.; Sun, Y.; Chen, L.; Hernandez, Y.; Feng, X.; Müllen, K. Sci. Rep. 2012, 2, 427. doi:10.1038/srep00427

158.Liang, J.; Huang, Y.; Oh, J.; Kozlov, M.; Sui, D.; Fang, S.; Baughman, R. H.; Ma, Y.; Chen, Y. Adv. Funct. Mater. 2011, 21, 3778-3784. doi:10.1002/adfm.201101072

159.Liang, J.; Xu, Y.; Sui, D.; Zhang, L.; Huang, Y.; Ma, Y.; Li, F.; Chen, Y. J. Phys. Chem. C 2010, 114, 17465-17471. doi:10.1021/jp105629r

160.Wu, C.; Zhang, H.; Wu, Y.-X.; Zhuang, Q.-C.; Tian, L.-L.; Zhang, X.-X. Electrochim. Acta 2014, 134, 18-27. doi:10.1016/j.electacta.2014.03.068

161.Hu, J.; Zheng, J.; Tian, L.; Duan, Y.; Lin, L.; Cui, S.; Peng, H.; Liu, T.; Guo, H.; Wang, X.; Pan, F. Chem. Commun. 2015, 51, 7855-7858. doi:10.1039/C5CC01195G

162.Jiang, X.; Yang, X.; Zhu, Y.; Yao, Y.; Zhao, P.; Li, C. J. Mater. Chem. A 2015, 3, 2361-2369. doi:10.1039/C4TA05913A

163.Zuo, Y.; Wang, G.; Peng, J.; Li, G.; Ma, Y.; Yu, F.; Dai, B.; Guo, X.; Wong, C.-P. J. Mater. Chem. A 2016, 4, 2453-2460. doi:10.1039/C5TA09742H

164.Su, Q.; Xie, D.; Zhang, J.; Du, G.; Xu, B. ACS Nano 2013, 7, 9115-9121. doi:10.1021/nn403720p

165.Wang, R.; Xu, C.; Sun, J.; Gao, L. Sci. Rep. 2014, 4, 7171. doi:10.1038/srep07171

166.Wang, R.; Xu, C.; Du, M.; Sun, J.; Gao, L.; Zhang, P.; Yao, H.; Lin, C. Small 2014, 10, 2260-2269. doi:10.1002/smll.201303371

167.Geng, Z.; Lin, Y.; Yu, X.; Shen, Q.; Ma, L.; Li, Z.; Pan, N.; Wang, X. J. Mater. Chem. 2012, 22, 3527-3535. doi:10.1039/c2jm15544c

168.Kim, H.; Seo, D.-H.; Kim, S.-W.; Kim, J.; Kang, K. Carbon 2011, 49, 326-332. doi:10.1016/j.carbon.2010.09.033

169.Zhu, J.; Sharma, Y.; Zeng, Z.; Zhang, X.; Srinivasan, M.; Mhaisalkar, S.; Zhang, H.; Hng, H.; Yan, Q. J. Phys. Chem. C 2011, 115, 8400-8406. doi:10.1021/jp2002113

170.Liang, Y.; Li, Y.; Wang, H.; Zhou, J.; Wang, J.; Regier, T.; Dai, H. Nat. Mater. 2011, 10, 780-786. doi:10.1038/nmat3087

171.Mao, S.; Wen, Z.; Huang, T.; Hou, Y.; Chen, J. Energy Environ. Sci. 2014, 7, 609-616. doi:10.1039/C3EE42696C

172.Wu, C.; Shen, Q.; Mi, R.; Deng, S.; Shu, Y.; Wang, H.; Liu, J.; Yan, H. J. Mater. Chem. A 2014, 2, 15987-15994. doi:10.1039/C4TA03313B

173.Wang, X.; Dong, X.; Wen, Y.; Li, C.; Xiong, Q.; Chen, P. Chem. Commun. 2012, 48, 6490-6492. doi:10.1039/c2cc32674d

174.Nie, R.; Shi, J.; Du, W.; Ning, W.; Hou, Z.; Xiao, F.-S. J. Mater. Chem. A 2013, 1, 9037-9045. doi:10.1039/c3ta11672g

175.Zhang, M.; Li, R.; Chang, X.; Xue, C.; Gou, X. J. Power Sources 2015, 290, 25-34. doi:10.1016/j.jpowsour.2015.04.178

176. Odedairo, T.; Yan, X.; Ma, J.; Jiao, Y.; Yao, X.; Du, A.; Zhu, Z. ACS Appl. Mater. Interfaces 2015, 7, 21373-21380. doi:10.1021/acsami.5b06063

177.Jin, H.; Wang, J.; Su, D.; Wei, Z.; Pang, Z.; Wang, Y. J. Am. Chem. Soc. 2015, 137, 2688-2694. doi:10.1021/ja5127165

178.Wu, Z.-S.; Ren, W.; Wen, L.; Gao, L.; Zhao, J.; Chen, Z.; Zhou, G.; Li, F.; Cheng, H.-M. ACS Nano 2010, 4, 3187-3194. doi:10.1021/nn100740x
179.Wang, R.; Xu, C.; Sun, J.; Liu, Y.; Gao, L.; Lin, C. Nanoscale 2013, 5, 6960-6967. doi:10.1039/c3nr01392h

180. Yao, Y.; Xu, C.; Qin, J.; Wei, F.; Rao, M.; Wang, S. Ind. Eng. Chem. Res. 2013, 52, 17341-17350. doi:10.1021/ie401690h 181.Fei, H.; Dong, J.; Arellano-Jiménez, M. J.; Ye, G.; Kim, N. D.; Samuel, E. L. G.; Peng, Z.; Zhu, Z.; Qin, F.; Bao, J.; Yacaman, M. J.; Ajayan, P. M.; Chen, D.; Tour, J. M. Nat. Commun. 2015, 6, 8668. doi:10.1038/ncomms9668

182. Singh, S. K.; Dhavale, V. M.; Kurungot, S. ACS Appl. Mater. Interfaces 2015, 7, 21138-21149. doi:10.1021/acsami.5b04865

183. Yao, Y.; Yang, Z.; Sun, H.; Wang, S. Ind. Eng. Chem. Res. 2012, 51, 14958-14965. doi:10.1021/ie301642g

184. Singh, S. K.; Dhavale, V. M.; Kurungot, S. ACS Appl. Mater. Interfaces 2015, 7, 442-451. doi:10.1021/am506450c

185. Yang, S.; Feng, X.; Ivanovici, S.; Müllen, K. Angew. Chem., Int. Ed. 2010, 49, 8408-8411. doi:10.1002/anie.201003485

186.Kumar, R.; Kim, H.-J.; Park, S.; Srivastava, A.; Oh, I.-K. Carbon 2014, 79, 192-202. doi:10.1016/j.carbon.2014.07.059

187.Sun, Y.; Hu, X.; Luo, W.; Huang, Y. J. Phys. Chem. C 2012, 116, 20794-20799. doi:10.1021/jp3070147

188.Zhu, Y. G.; Wang, Y.; Shi, Y.; Huang, Z. X.; Fu, L.; Yang, H. Y. Adv. Energy Mater. 2014, 4, 1301788. doi:10.1002/aenm.201301788

189.Guo, S.; Zhang, S.; Wu, L.; Sun, S. Angew. Chem., Int. Ed. 2012, 51, 11770-11773. doi:10.1002/anie.201206152

190.Zhao, Y.; Sun, B.; Huang, X.; Liu, H.; Su, D.; Sun, K.; Wang, G. J. Mater. Chem. A 2015, 3, 5402-5408. doi:10.1039/C5TA00158G

191.Ci, S.; Mao, S.; Huang, T.; Wen, Z.; Steeber, D. A.; Chen, J. Electroanalysis 2014, 26, 1326-1334. doi:10.1002/elan.201300645

192.Wang, M.; Huang, J.; Wang, M.; Zhang, D.; Chen, J. Food Chem. 2014, 151, 191-197. doi:10.1016/j.foodchem.2013.11.046

193. Yao, Y.; Xu, C.; Miao, S.; Sun, H.; Wang, S. J. Colloid Interface Sci. 2013, 402, 230-236. doi:10.1016/j.jcis.2013.03.070

194. Lo Nigro, R.; Battiato, S.; Greco, G.; Fiorenza, P.; Roccaforte, F.; Malandrino, G. Thin Solid Films 2014, 563, 50-55. doi:10.1016/j.tsf.2014.04.012

195.Xia, X.; Tu, J.; Mai, Y.; Chen, R.; Wang, X.; Gu, C.; Zhao, X. Chem. - Eur. J. 2011, 17, 10898-10905. doi:10.1002/chem.201100727

196.Cai, G.-f.; Tu, J.-p.; Zhang, J.; Mai, Y.-j.; Lu, Y.; Gu, C.-d.; Wang, X.-I. Nanoscale 2012, 4, 5724-5730. doi:10.1039/c2nr31397a

197. Huang, X. H.; Zhang, P.; Wu, J. B.; Lin, Y.; Guo, R. Q. Mater. Lett. 2015, 153, 102-105. doi:10.1016/j.matlet.2015.04.016

198. Mai, Y. J.; Shi, S. J.; Zhang, D.; Lu, Y.; Gu, C. D.; Tu, J. P. J. Power Sources 2012, 204, 155-161. doi:10.1016/j.jpowsour.2011.12.038

199.Zhou, G.; Wang, D.-W.; Yin, L.-C.; Li, N.; Li, F.; Cheng, H.-M. ACS Nano 2012, 6, 3214-3223. doi:10.1021/nn300098m

200.Zhao, B.; Song, J.; Liu, P.; Xu, W.; Fang, T.; Jiao, Z.; Zhang, H.; Jiang, Y. J. Mater. Chem. 2011, 21, 18792-18798. doi:10.1039/c1jm13016a

201.Jiang, Y.; Chen, D.; Song, J.; Jiao, Z.; Ma, Q.; Zhang, H.; Cheng, L.; Zhao, B.; Chu, Y. Electrochim. Acta 2013, 91, 173-178. doi:10.1016/j.electacta.2012.12.032

202. Kottegoda, I. R. M.; Idris, N. H.; Lu, L.; Wang, J.-Z.; Liu, H.-K. Electrochim. Acta 2011, 56, 5815-5822. doi:10.1016/j.electacta.2011.03.143 
203.Wu, C.; Deng, S.; Wang, H.; Sun, Y.; Liu, J.; Yan, H. ACS Appl. Mater. Interfaces 2014, 6, 1106-1112. doi:10.1021/am404691w

204.Hoa, L. T.; Tien, H. N.; Luan, V. H.; Chung, J. S.; Hur, S. H. Sens. Actuators, B 2013, 185, 701-705. doi:10.1016/j.snb.2013.05.050

205.Lv, W.; Jin, F.-M.; Guo, Q. G.; Yang, Q.-H.; Kang, F. Electrochim. Acta 2012, 73, 129-135. doi:10.1016/j.electacta.2011.11.089

206.Kumar, R.; Singh, R. K.; Savu, R.; Dubey, P. K.; Kumar, P.; Moshkalev, S. A. RSC Adv. 2016, 6, 26612-26620. doi:10.1039/C6RA00426A

207.Wang, H.; Casalongue, H. S.; Liang, Y.; Dai, H. J. Am. Chem. Soc. 2010, 132, 7472-7477. doi:10.1021/ja102267j

208.Wang, H.; Robinson, J. T.; Diankov, G.; Dai, H. J. Am. Chem. Soc. 2010, 132, 3270-3271. doi:10.1021/ja100329d

209.Liang, J.; Bi, H.; Wan, D.; Huang, F. Adv. Funct. Mater. 2012, 22 , 1267-1271. doi:10.1002/adfm.201102809

210.Kholmanov, I. N.; Domingues, S. H.; Chou, H.; Wang, X.; Tan, C.; Kim, J.-Y.; Li, H.; Piner, R.; Zarbin, A. J. G.; Ruoff, R. S. ACS Nano 2013, 7, 1811-1816. doi:10.1021/nn3060175

211.Liu, M.; Liu, R.; Chen, W. Biosens. Bioelectron. 2013, 45, 206-212. doi:10.1016/j.bios.2013.02.010

212.Ding, J.; Sun, W.; Wei, G.; Su, Z. RSC Adv. 2015, 5, 35338-35345. doi:10.1039/C5RA04164C

213. Ortega-Amaya, R.; Matsumoto, Y.; Espinoza-Rivas, A. M.; Pérez-Guzmán, M. A.; Ortega-López, M. Beilstein J. Nanotechnol. 2016, 7, 1010-1017. doi:10.3762/bjnano.7.93

214.Deng, S.; Tjoa, V.; Fan, H. M.; Tan, H. R.; Sayle, D. C.; Olivo, M.; Mhaisalkar, S.; Wei, J.; Sow, C. H. J. Am. Chem. Soc. 2012, 134, 4905-4917. doi:10.1021/ja211683m

215.Mai, Y. J.; Wang, X. L.; Xiang, J. Y.; Qiao, Y. Q.; Zhang, D.; Gu, C. D.; Tu, J. P. Electrochim. Acta 2011, 56, 2306-2311. doi:10.1016/j.electacta.2010.11.036

216. Mathesh, M.; Liu, J.; Nam, N. D.; Lam, S. K. H.; Zheng, R.; Barrow, C. J.; Yang, W. J. Mater. Chem. C 2013, 1, 3084-3090. doi:10.1039/c3tc30180j

217.Singh, B.; Mehta, B. R.; Govind; Feng, X.; Müllen, K. Appl. Phys. Lett. 2011, 99, 222109. doi:10.1063/1.3663971

218.Zhou, W.; Zhang, F.; Liu, S.; Wang, J.; Du, X.; Yin, D.; Wang, L. RSC Adv. 2014, 4, 51362-51365. doi:10.1039/C4RA09144B

219.Sun, C.-L.; Cheng, W.-L.; Hsu, T.-K.; Chang, C.-W.; Chang, J.-L.; Zen, J.-M. Electrochem. Commun. 2013, 30, 91-94. doi:10.1016/j.elecom.2013.02.015

220.Wang, Z.; Xiao, Y.; Cui, X.; Cheng, P.; Wang, B.; Gao, Y.; Li, X.; Yang, T.; Zhang, T.; Lu, G. ACS Appl. Mater. Interfaces 2014, 6, 3888-3895. doi:10.1021/am404858z

221.Ko, J. W.; Kim, S.-W.; Hong, J.; Ryu, J.; Kang, K.; Park, C. B. Green Chem. 2012, 14, 2391-2394. doi:10.1039/c2gc35560d

222.Purushothaman, K. K.; Saravanakumar, B.; Babu, I. M.; Sethuraman, B.; Muralidharan, G. RSC Adv. 2014, 4, 23485-23491. doi:10.1039/c4ra02107j

223.Zhao, B.; Liu, P.; Zhuang, H.; Jiao, Z.; Fang, T.; Xu, W.; Lu, B.; Jiang, Y. J. Mater. Chem. A 2013, 1, 367-373. doi:10.1039/C2TA00084A

224.Son, D. I.; Kwon, B. W.; Park, D. H.; Seo, W.-S.; Yi, Y.; Angadi, B.; Lee, C.-L.; Choi, W. K. Nat. Nanotechnol. 2012, 7, 465-471. doi:10.1038/nnano.2012.71

225. Bu, Y.; Chen, Z.; Li, W.; Hou, B. ACS Appl. Mater. Interfaces 2013, 5 , 12361-12368. doi:10.1021/am403149g
226. Shao, D.; Yu, M.; Sun, H.; Hu, T.; Lian, J.; Sawyer, S. Nanoscale 2013, 5, 3664-3667. doi:10.1039/c3nr00369h

227.Zhou, X.; Shi, T.; Zhou, H. Appl. Surf. Sci. 2012, 258, 6204-6211. doi:10.1016/j.apsusc.2012.02.131

228. Han, M.; Yin, X.; Kong, L.; Li, M.; Duan, W.; Zhang, L.; Cheng, L. J. Mater. Chem. A 2014, 2, 16403-16409. doi:10.1039/C4TA03033H

229.Zhong, L. L.; Yun, K. Int. J. Nanomed. 2015, 10, 79-92.

230. Yang, Y.; Liu, T. Appl. Surf. Sci. 2011, 257, 8950-8954. doi:10.1016/j.apsusc.2011.05.070

231.Lin, J.; Penchev, M.; Wang, G.; Paul, R. K.; Zhong, J.; Jing, X.; Ozkan, M.; Ozkan, C. S. Small 2010, 6, 2448-2452. doi:10.1002/smll.201000250

232. Ameen, S.; Akhtar, M. S.; Song, M.; Shin, H. S. ACS Appl. Mater. Interfaces 2012, 4, 4405-4412. doi:10.1021/am301064j

233. Akhavan, O. ACS Nano 2010, 4, 4174-4180. doi:10.1021/nn1007429

234.Hwang, J. O.; Lee, D. H.; Kim, J. Y.; Han, T. H.; Kim, B. H.; Park, M.; No, K.; Kim, S. O. J. Mater. Chem. 2011, 21, 3432-3437. doi:10.1039/C0JM01495H

235. Kim, Y.-J.; Hadiyawarman, Y.; oon, A.; Kim, M.; Yi, G.-C.; Liu, C. Nanotechnology 2011, 22, 245603. doi:10.1088/0957-4484/22/24/245603

236.Zou, R.; He, G.; Xu, K.; Liu, Q.; Zhang, Z.; Hu, J. J. Mater. Chem. A 2013, 1, 8445-8452. doi:10.1039/c3ta11490b

237.Kim, Y.-J.; Lee, J.-H.; Yi, G.-C. Appl. Phys. Lett. 2009, 95, 213101. doi:10.1063/1.3266836

238. Kim, Y.-J.; Yoo, H.; Lee, C.-H.; Park, J. B.; Baek, H.; Kim, M.; Yi, G.-C. Adv. Mater. 2012, 24, 5565-5569. doi:10.1002/adma.201201966

239. Yin, Z.; Wu, S.; Zhou, X.; Huang, X.; Zhang, Q.; Boey, F.; Zhang, H. Small 2010, 6, 307-312. doi:10.1002/smll.200901968

240.Li, S.; Xiao, Y.; Wang, X.; Cao, M. Phys. Chem. Chem. Phys. 2014, 16, 25846-25853. doi:10.1039/C4CP03964E

241.Djurišić, A. B.; Leung, Y. H. Small 2006, 2, 944-961. doi:10.1002/smll.200600134

242.Hwang, S. W.; Shin, D. H.; Kim, C. O.; Hong, S. H.; Kim, M. C.; Kim, J.; Lim, K. Y.; Kim, S.; Choi, S.-H.; Ahn, K. J.; Kim, G.; Sim, S. H.; Hong, B. H. Phys. Rev. Lett. 2010, 105, 127403. doi:10.1103/PhysRevLett.105.127403

243. Kavitha, M. K.; Gopinath, P.; John, H. Phys. Chem. Chem. Phys. 2015, 17, 14647-14655. doi:10.1039/C5CP01318F

244.Pham, C. V.; Repp, S.; Thomann, R.; Krueger, M.; Weber, S.; Erdem, E. Nanoscale 2016, 8, 9682-9687. doi:10.1039/C6NR00393A

245.Tien, H. N.; Luan, V. H.; Hoa, L. T.; Khoa, N. T.; Hahn, S. H.; Chung, J. S.; Shin, E. W.; Hur, S. H. Chem. Eng. J. 2013, 229, 126-133. doi:10.1016/j.cej.2013.05.110

246. Williams, G.; Kamat, P. V. Langmuir 2009, 25, 13869-13873. doi:10.1021/la900905h

247.Lin, S. S.; Chen, B. G.; Xiong, W.; Yang, Y.; He, H. P.; Luo, J. Opt. Express 2012, 20, A706-A712. doi:10.1364/OE.20.00A706

248.Sun, L.; Zhou, X.; Zhang, Y.; Guo, T. J. Alloys Compd. 2015, 632, 604-608. doi:10.1016/j.jallcom.2015.01.105

249.Lin, J.-C.; Huang, B.-R.; Lin, T.-C. Appl. Surf. Sci. 2014, 289, 384-387. doi:10.1016/j.apsusc.2013.10.171

250.Kavitha, M. K.; John, H.; Gopinath, P.; Philip, R. J. Mater. Chem. C 2013, 1, 3669-3676. doi:10.1039/c3tc30323c

251.Guo, W.; Xu, S.; Wu, Z.; Wang, N.; Loy, M. M. T.; Du, S. Small 2013, 9, 3914. doi:10.1002/smll.201302443

252. Ye, Y.; Dai, L.; Gan, L.; Meng, H.; Dai, Y.; Guo, X.; Qin, G. Nanoscale Res. Lett. 2012, 7, 218. doi:10.1186/1556-276X-7-218 
253.Ahmad, M.; Ahmed, E.; Hong, Z. L.; Xu, J. F.; Khalid, N. R.; Elhissi, A.; Ahmed, W. Appl. Surf. Sci. 2013, 274, 273-281. doi:10.1016/j.apsusc.2013.03.035

254.Fan, F.; Wang, X.; Ma, Y.; Fu, K.; Yang, Y. Fullerenes, Nanotubes, Carbon Nanostruct. 2015, 23, 917-921. doi:10.1080/1536383X.2015.1013187

255.Lv, T.; Pan, L.; Liu, X.; Sun, Z. Catal. Sci. Technol. 2012, 2, 2297-2301. doi:10.1039/c2cy20023f

256.Tian, J.; Liu, S.; Li, H.; Wang, L.; Zhang, Y.; Luo, Y.; Asiri, A. M.; Al-Youbi, A. O.; Sun, X. RSC Adv. 2012, 2, 1318-1321. doi:10.1039/c2ra01114j

257.Zhang, L.; Du, L.; Cai, X.; Yu, X.; Zhang, D.; Liang, L.; Yang, P.; Xing, X.; Mai, W.; Tan, S.; Gu, Y.; Song, J. Physica E 2013, 47, 279-284. doi:10.1016/j.physe.2012.10.008

258.Wei, A.; Xiong, L.; Sun, L.; Liu, Y.; Li, W.; Lai, W.; Liu, X.; Wang, L.; Huang, W.; Dong, X. Mater. Res. Bull. 2013, 48, 2855-2860. doi:10.1016/j.materresbull.2013.04.012

259.Fu, D.; Han, G.; Yang, F.; Zhang, T.; Chang, Y.; Liu, F. Appl. Surf. Sci. 2013, 283, 654-659. doi:10.1016/j.apsusc.2013.07.003

260.Li, B.; Cao, H. J. Mater. Chem. 2011, 21, 3346-3349. doi:10.1039/C0JM03253K

261.Malekshoar, G.; Pal, K.; He, Q.; Yu, A.; Ray, A. K. Ind. Eng. Chem. Res. 2014, 53, 18824-18832. doi:10.1021/ie501673v

262.Singh, G.; Choudhary, A.; Haranath, D.; Joshi, A. G.; Singh, N.; Singh, S.; Pasricha, R. Carbon 2012, 50, 385-394. doi:10.1016/j.carbon.2011.08.050

263.Zhang, D.; Yin, N.; Xia, B. J. Mater. Sci.: Mater. Electron. 2015, 26 , 5937-5945. doi:10.1007/s10854-015-3165-2

264.Liu, S.; Yu, B.; Zhang, H.; Fei, T.; Zhang, T. Sens. Actuators, B 2014, 202, 272-278. doi:10.1016/j.snb.2014.05.086

265. Huang, Q.; Zeng, D.; Li, H.; Xie, C. Nanoscale 2012, 4, 5651-5658. doi:10.1039/c2nr31131c

266.Mu, H.; Zhang, Z.; Zhao, X.; Liu, F.; Wang, K.; Xie, H. Appl. Phys. Lett. 2014, 105, 033107. doi:10.1063/1.4890583

267. Anand, K.; Singh, O.; Singh, M. P.; Kaur, J.; Singh, R. C. Sens. Actuators, B 2014, 195, 409-415. doi:10.1016/j.snb.2014.01.029

268.Zhang, D.; Liu, J.; Xia, B. IEEE Electron Device Lett. 2016, 37, 916-919. doi:10.1109/LED.2016.2565728

269. Liu, X.; Pan, L.; Lv, T.; Lu, T.; Zhu, G.; Sun, Z.; Sun, C. Catal. Sci. Technol. 2011, 1, 1189-1193. doi:10.1039/c1cy00109d

270.Liua, X.; Pana, L.; Zhao, Q.; Lv, T.; Zhua, G.; Chena, T.; Lua, T.; Suna, Z.; Sun, C. Chem. Eng. J. 2012, 183, 238-243. doi:10.1016/j.cej.2011.12.068

271.Uddin, A. S. M. I.; Lee, K.-W.; Chung, G.-S. Sens. Actuators, B 2015, 216, 33-40. doi:10.1016/j.snb.2015.04.028

272.Kushima, A.; Liu, X. H.; Zhu, G.; Wang, Z. L.; Huang, J. Y.; Li, J. Nano Lett. 2011, 11, 4535-4541. doi:10.1021/nl201376j

273.Sun, X.; Zhou, C.; Xie, M.; Sun, H.; Hu, T.; Lu, F.; Scott, S. M.; George, S. M.; Lian, J. J. Mater. Chem. A 2014, 2, 7319-7326. doi:10.1039/C4TA00589A

274.Song, W. T.; Xie, J.; Liu, S. Y.; Zheng, Y. X.; Cao, G. S.; Zhu, T. J.; Zhao, X. B. Int. J. Electrochem. Sci. 2012, 7, 2164-2174.

275.Boruah, B. D.; Mukherjee, A.; Sridhar, S.; Misra, A. ACS Appl. Mater. Interfaces 2015, 7, 10606-10611. doi:10.1021/acsami.5b02403

276.Palanisamy, S.; Chen, S.-M.; Sarawathi, R. Sens. Actuators, B 2012, 166-167, 372-377. doi:10.1016/j.snb.2012.02.075

277.Ding, J.; Zhu, S.; Zhu, T.; Sun, W.; Li, Q.; Wei, G.; Su, Z. RSC Adv. 2015, 5, 22935-22942. doi:10.1039/C5RA00884K
278. Kavitha, T.; Gopalan, A. I.; Lee, K.-P.; Park, S.-Y. Carbon 2012, 50, 2994-3000. doi:10.1016/j.carbon.2012.02.082

279. Choi, W. M.; Shin, K.-S.; Lee, H. S.; Choi, D.; Kim, K.; Shin, H.-J.; Yoon, S.-M.; Choi, J.-Y.; Kim, S.-W. Nano Res. 2011, 4, 440-447. doi:10.1007/s12274-011-0100-6

280.Lee, J. M.; Pyun, Y. B.; Yi, J.; Choung, J. W.; Park, W. I. J. Phys. Chem. C 2009, 113, 19134-19138. doi:10.1021/jp9078713

281. AbdulAlmohsin, S.; Cui, J. B. J. Phys. Chem. C 2012, 116, 9433-9438. doi:10.1021/jp301881s

282.Park, H.; Chang, S.; Jean, J.; Cheng, J. J.; Araujo, P. T.; Wang, M.; Bawendi, M. G.; Dresselhaus, M. S.; Bulović, V.; Kong, J.; Gradečak, S. Nano Lett. 2013, 13, 233-239. doi:10.1021/nl303920b

283. Fouda, A. N.; El Basaty, A. B.; Eid, E. A. Nanoscale Res. Lett. 2016, 11, 13. doi:10.1186/s11671-015-1221-8

284.Padhi, A. K.; Nanjundaswamy, K. S.; Goodenough, J. B. J. Electrochem. Soc. 1997, 144, 1188-1194. doi:10.1149/1.1837571

285.Hu, L.-H.; Wu, F.-Y.; Lin, C.-T.; Khlobystov, A. N.; Li, L.-J. Nat. Commun. 2013, 4, 1687. doi:10.1038/ncomms2705

286. Fan, Q.; Lei, L.; Xu, X.; Yin, G.; Sun, Y. J. Power Sources 2014, 257, 65-69. doi:10.1016/j.jpowsour.2014.01.044

287.Guo, X.; Fan, Q.; Yu, L.; Liang, J.; Ji, W.; Peng, L.; Guo, X.; Ding, W.; Chen, Y. J. Mater. Chem. A 2013, 1, 11534-11538. doi:10.1039/c3ta12422c

288. Kim, W.; Ryu, W.; Han, D.; Lim, S.; Eom, J.; Kwon, H. ACS Appl. Mater. Interfaces 2014, 6, 4731-4736. doi:10.1021/am405335k

289. Praneetha, S.; Murugan, A. V. RSC Adv. 2013, 3, 25403-25409. doi:10.1039/c3ra44133d

290. Yang, J.; Wang, J.; Tang, Y.; Wang, D.; Li, X.; Hu, Y.; Li, R.; Liang, G.; Sham, T.-K.; Sun, X. Energy Environ. Sci. 2013, 6, 1521-1528. doi:10.1039/c3ee24163g

291. Yang, J.; Wang, J.; Wang, D.; Li, X.; Geng, D.; Liang, G.; Gauthier, M.; Li, R.; Sun, X. J. Power Sources 2012, 208, 340-344. doi:10.1016/j.jpowsour.2012.02.032

292.Zhang, Y.; Wang, W.; Li, P.; Fu, Y.; Ma, X. J. Power Sources 2012, 210, 47-53. doi:10.1016/j.jpowsour.2012.03.007

293.Shi, Y.; Wang, J.-Z.; Chou, S.-L.; Wexler, D.; Li, H.-J.; Ozawa, K.; Liu, H.-K.; Wu, Y.-P. Nano Lett. 2013, 13, 4715-4720. doi:10.1021/nl402237u

294.Wang, H.; Liao, X.-Z.; Li, L.; Chen, H.; Jiang, Q.-Z.; He, Y.-S.; Ma, Z.-F. J. Electrochem. Soc. 2012, 159, A1874-A1879. doi:10.1149/2.012212jes

295. Kim, J. G.; Kim, Y.; Noh, Y.; Kim, W. B. ChemSusChem 2015, 8, 1752-1760. doi:10.1002/cssc.201500123

296.Wang, D.; Zhang, Q.; Zhou, K.; Yang, W.; Hu, Y.; Gong, X. J. Hazard. Mater. 2014, 278, 391-400. doi:10.1016/j.jhazmat.2014.05.072

297.Mohamed, S. G.; Tsai, Y.-Q.; Chen, C.-J.; Tsai, Y.-T.; Hung, T.-F.; Chang, W.-S.; Liu, R.-S. ACS Appl. Mater. Interfaces 2015, 7, 12038-12046. doi:10.1021/acsami.5b02180

298. Ratha, S.; Samantara, A. K.; Rout, C. S.; Jena, B. K. J. Solid State Electrochem. 2016, 20, 285-291. doi:10.1007/s10008-015-3035-0

299.Zhang, G.; Xia, B. Y.; Wang, X.; Lou, X. W. Adv. Mater. 2014, 26, 2408-2412. doi:10.1002/adma.201304683

300.Umeshbabu, E.; Rajeshkhanna, G.; Rao, G. R. J. Solid State Electrochem. 2016, 20, 1837-1844. doi:10.1007/s10008-015-3022-5 
301.Gong, H.; Xue, H.; Wang, T.; Guo, H.; Fan, X.; Song, L.; Xia, W.; $\mathrm{He}, \mathrm{J}$. ACS Appl. Mater. Interfaces 2016, 8, 18060-18068. doi:10.1021/acsami.6b04810

302.Wu, M.; Meng, S.; Wang, Q.; Si, W.; Huang, W.; Dong, X. ACS Appl. Mater. Interfaces 2015, 7, 21089-21094. doi:10.1021/acsami.5b06299

303.Lee, D. U.; Kim, B. J.; Chen, Z. J. Mater. Chem. A 2013, 1, 4754-4762. doi:10.1039/c3ta01402a

304.Zhang, H.; Li, H.; Wang, H.; He, K.; Wang, S.; Tang, Y.; Chen, J. J. Power Sources 2015, 280, 640-648. doi:10.1016/j.jpowsour.2015.01.147

305.Chen, Y.; Zhu, J.; Qu, B.; Lu, B.; Xu, Z. Nano Energy 2014, 3, 88-94. doi:10.1016/j.nanoen.2013.10.008

306.Wang, Z.; Zhang, X.; Zhang, Z.; Qiao, N.; Li, Y.; Hao, Z. J. Colloid Interface Sci. 2015, 460, 303-309. doi:10.1016/j.jcis.2015.08.067

307.Wei, Y.; Chen, S.; Su, D.; Sun, B.; Zhu, J.; Wang, G. J. Mater. Chem. A 2014, 2, 8103-8109. doi:10.1039/c3ta15423h

308. Liu, Q.; Jin, J.; Zhang, J. ACS Appl. Mater. Interfaces 2013, 5, 5002-5008. doi:10.1021/am4007897

309.Ning, R.; Tian, J.; Asiri, A. M.; Qusti, A. H.; Al-Youbi, A. O.; Sun, X. Langmuir 2013, 29, 13146-13151. doi:10.1021/la4031014

310.Bai, S.; Shen, X.; Zhong, X.; Liu, Y.; Zhu, G.; Xu, X.; Chen, K. Carbon 2012, 50, 2337-2346. doi:10.1016/j.carbon.2012.01.057

311.Yao, Y.; Cai, Y.; Lu, F.; Wei, F.; Wang, X.; Wang, S. J. Hazard. Mater. 2014, 270, 61-70. doi:10.1016/j.jhazmat.2014.01.027

312.Cai, W.; Lai, T.; Dai, W.; Ye, J. J. Power Sources 2014, 255, 170-178. doi:10.1016/j.jpowsour.2014.01.027

313. Yamaguchi, N. U.; Bergamasco, R.; Hamoudi, S. Chem. Eng. J. 2016, 295, 391-402. doi:10.1016/j.cej.2016.03.051

314.Kumar, S.; Nair, R. R.; Pillai, P. B.; Gupta, S. N.; lyengar, M. A. R.; Sood, A. K. ACS Appl. Mater. Interfaces 2014, 6, 17426-17436. doi:10.1021/am504826q

315.Fu, M.; Jiao, Q.; Zhao, Y.; Li, H. J. Mater. Chem. A 2014, 2, 735-744. doi:10.1039/C3TA14050D

316.Zong, M.; Huang, Y.; Wu, H.; Zhao, Y.; Wang, Q.; Sun, X. Mater. Lett. 2014, 114, 52-55. doi:10.1016/j.matlet.2013.09.113

317.Liu, S.; Xie, J.; Fang, C.; Cao, G.; Zhu, T.; Zhao, X. J. Mater. Chem. 2012, 22, 19738-19743. doi:10.1039/c2jm34019d

318.Wang, B.; Li, S.; Liu, J.; Yu, M.; Li, B.; Wu, X. Electrochim. Acta 2014, 146, 679-687. doi:10.1016/j.electacta.2014.08.106

319.Zhang, Z.; Li, W.; Zou, R.; Kang, W.; Chui, Y. S.; Yuen, M. F.; Lee, C.-S.; Zhang, W. J. Mater. Chem. A 2015, 3, 6990-6997. doi:10.1039/C5TA00073D

320.Yao, Y.; Yang, Z.; Zhang, D.; Peng, W.; Sun, H.; Wang, S. Ind. Eng. Chem. Res. 2012, 51, 6044-6051. doi:10.1021/ie300271p

321.Li, N.; Zheng, M.; Chang, X.; Ji, G.; Lu, H.; Xue, L.; Pan, L.; Cao, J. J. Solid State Chem. 2011, 184, 953-958. doi:10.1016/j.jssc.2011.01.014

322.He, G.; Ding, J.; Zhang, J.; Hao, Q.; Chen, H. Ind. Eng. Chem. Res. 2015, 54, 2862-2867. doi:10.1021/ie504706w

323.Zhang, D.; Pu, X.; Gao, Y.; Su, C.; Li, H.; Li, H.; Hang, W. Mater. Lett. 2013, 113, 179-181. doi:10.1016/j.matlet.2013.09.088

324.Xu, L. J.; Chu, W.; Gan, L. Chem. Eng. J. 2015, 263, 435-443. doi:10.1016/j.cej.2014.11.065

325.Zhao, Y.; He, G.; Dai, W.; Chen, H. Ind. Eng. Chem. Res. 2014, 53, 12566-12574. doi:10.1021/ie501624u

326.Zhao, C.; Yu, C.; Liu, S.; Yang, J.; Fan, X.; Qiu, J.

Part. Part. Syst. Charact. 2015, 32, 91-97.

doi:10.1002/ppsc.201400114
327. Li, X.; Feng, J.; Zhu, H.; Qu, C.; Bai, J.; Zheng, X. RSC Adv. 2014, 4, 33619-33625. doi:10.1039/C4RA06732K

328. Mahmood, N.; Zhang, C.; Liu, F.; Zhu, J.; Hou, Y. ACS Nano 2013, 7, 10307-10318. doi:10.1021/nn4047138

329.Xing, Z.; Ju, Z.; Yang, J.; Xu, H.; Qian, Y. Nano Res. 2012, 5, 477-485. doi:10.1007/s12274-012-0233-2

330.Wang, B.; Li, S.; Li, B.; Liu, J.; Yu, M. New J. Chem. 2015, 39, 1725-1733. doi:10.1039/C4NJ01802H

331.Fu, Y.; Wang, X. Ind. Eng. Chem. Res. 2011, 50, 7210-7218. doi:10.1021/ie200162a

332. Hou, Y.; Li, X.; Zhao, Q.; Chen, G. Appl. Catal., B 2013, 142-143, 80-88. doi:10.1016/j.apcatb.2013.04.062

333.Song, W.; Xie, J.; Liu, S.; Cao, G.; Zhu, T.; Zhao, X. New J. Chem. 2012, 36, 2236-2241. doi:10.1039/c2nj40534b

334.Yao, Y.; Qin, J.; Cai, Y.; Wei, F.; Lu, F.; Wang, S. Environ. Sci. Pollut. Res. 2014, 21, 7296-7306. doi:10.1007/s11356-014-2645-x

335.Sun, L.; Zhao, Z.; Zhou, Y.; Liu, L. Nanoscale 2012, 4, 613-620. doi:10.1039/C1NR11411E

336.Liu, Y.; Wang, W.; Gu, L.; Wang, Y.; Ying, Y.; Mao, Y.; Sun, L.; Peng, X. ACS Appl. Mater. Interfaces 2013, 5, 9850-9855. doi:10.1021/am403136e

\section{License and Terms}

This is an Open Access article under the terms of the Creative Commons Attribution License (http://creativecommons.org/licenses/by/4.0), which permits unrestricted use, distribution, and reproduction in any medium, provided the original work is properly cited.

The license is subject to the Beilstein Journal of

Nanotechnology terms and conditions:

(http://www.beilstein-journals.org/bjnano)

The definitive version of this article is the electronic one which can be found at:

doi:10.3762/bjnano.8.74 